\title{
¿Hacia una responsabilidad objetiva del Estado que «no puede» combatir el terrorismo internacional?*
}

\author{
Towards a strict liability of States «unable» to fight international \\ terrorism?
}

\author{
Andrea CocCHINI \\ Ayudante doctor de Derecho internacional público y Relaciones internacionales \\ Universidad de Navarra \\ acocchini@unav.es
}

\begin{abstract}
Resumen: La vertiente siria de la operación Determinación absoluta contra la organización terrorista del Daesh ha vuelto a poner sobre el tapete la licitud de la teoría del Estado que «no quiere o no puede» combatir de manera eficaz las organizaciones terroristas presentes en su territorio. A partir de los atentados del 11-S, la práctica de los Estados ha demostrado una tendencia creciente a ensanchar los límites del derecho de legítima defensa del artículo 51 de la Carta de las Naciones Unidas. En el presente estudio se sostiene que, después de una primera ampliación (posterior al 11-S) de la legítima defensa, está dándose una segunda que, fundamentada en la teoría del Estado que «no quiere o no puede», justificaría el recurso a la fuerza militar frente a la responsabilidad objetiva o indirecta del Estado territorial.
\end{abstract}

Palabras clave: Estado que no quiere o no puede, responsabilidad objetiva, legítima defensa, terrorismo internacional, uso de la fuerza, Daesh, Siria.

\begin{abstract}
Operation Inherent resolve against ISIL in Syria has revitalised the debate on the legitimacy of the «unwilling or unable» State theory. Starting from 9/11 terrorist attacks, States' practice has shown a growing tendency to expand the right of self-defence of Article 51 of the U.N: Charter. Thus, the present study primarily revises the first extension of self-defence that took place after $9 / 11$ allowing its invocation against the State that shelters a terrorist group. Moreover, it analyses a second expansion of the right of self-defence based on the «unwilling or unable» theory which seems to trespass into States' strict liability for not preventing terrorists attacks originating from their territory.
\end{abstract}

Keywords: unwilling or unable State, strict liability, self-defence, international terrorism, use of force, ISIL, Syria

Sumario: 1. INTRODUCCIÓN. 2. LA REAPARACIÓN DE LA TEORÍA DEL ESTADO QUE «NO QUIERE O NO PUEDE»COMBATIR EL TERRORISMO FRENTE A LA CONSOLIDACIÓN DEL DAESH. 3. LA ATRIBUCIÓN DE LA RESPONSABILIDAD DIRECTA AL ESTADO TERRITORIAL POR LOS ACTOS TERRORISTAS ORIGINADOS BAJO SU JURISDICCIÓN. 4. LA CRISIS SIN REMEDIO DE LOS CRITERIOS TÍPICOS DE ATRIBUCIÓN DE LA RESPONSABILIDAD INTERNACIONAL FRENTE AL TERRORISMO CONTEMPORÁNEO. 5. LA LEGÍTIMA DEFENSA EN SIRIA: ¿UNA RESPONSABILIDAD OBJETIVA INTERNACIONAL DEL ESTADO QUE «NO PUEDE» COMBATIR EL TERRORISMO EN SU TERRITORIO? 6. CONCLUSIONES. 7. REFERENCIAS BIBLIOGRÁFICAS PRINCIPALES.

* Todas las páginas web de referencia han sido consultadas por última vez el 10 de enero de 2019. 


\section{INTRODUCCIÓN}

$L$ a amenaza representada por la organización terrorista del «Estado Islámico» (Daesh) ha vuelto a centrar el debate internacional acerca de la licitud de la doctrina del Estado que «no quiere o no puede» (unwilling or unable) enfrentarse a los actores privados que acampan a sus anchas en su territorio. Algunos de los Estados parte en la operación Determinación absoluta contra el Daesh en Siria utilizaron, directa o indirectamente, esta doctrina para explicar la intervención armada en territorio sirio, a falta de otros argumentos jurídicos que la justificasen. Sin embargo, es una teoría controvertida porque propone que el Estado víctima de acciones terroristas pueda recurrir a la legítima defensa del artículo 51 de la Carta de las Naciones Unidas (ONU) en el Estado que «no quiere o no puede» enfrentarse al terrorismo en su jurisdicción territorial. Admitiría, por tanto, una ampliación importante del elemento de la «atribución», necesario para imputar la responsabilidad internacional a un Estado por actos ilícitos de un actor no estatal como es una organización terrorista.

El presente trabajo analiza si es lícita esta ampliación de la legítima defensa que permita la invocación de la teoría frente al Estado que «no quiere» y (sobre todo) «no puede» atajar el terrorismo y si, en consecuencia, estaría imponiéndose la responsabilidad «objetiva» e «indirecta» (strict/vicarious liability) del Estado que infringe la obligación de prevenir los ataques terroristas. Para ello, la sección 2 desgrana el contenido esencial de la teoría del Estado que «no quiere o no puede» y las razones de su reaparición en la doctrina y en la práctica internacional de los últimos años. La sección 3 profundiza en los supuestos consolidados en el Derecho internacional para poder atribuir a un Estado la responsabilidad internacional como consecuencia de las acciones terroristas de un actor no estatal que actúa desde su territorio. En la sección 4, se explica cómo y por qué los criterios de atribución de la responsabilidad internacional del Estado por hecho ilícito parecen haber entrado en crisis después de los atentados del 11 de septiembre de 2001 (11-S) y cómo la actual intervención militar en Siria representa el golpe decisivo para su afirmación dado a la interpretación tradicional de la noción de «atribución» de la responsabilidad internacional. La sección 5 analiza si la invocación frecuente de la teoría del Estado que «no quiere o no puede» está favoreciendo la aparición de una responsabilidad objetiva e indirecta de los Estados en cuyos territorios anidan grupos terroristas que actúan en el extranjero. Por último, la sección 6 propone algunas conclusiones sobre la posible licitud de la teoría del Estado 
que «no quiere o no puede» y del reconocimiento paulatino de la responsabilidad objetiva de un Estado por los atentados organizados y perpetrados desde su jurisdicción.

\section{LA REAPARICIÓN DE LA TEORÍA DEL ESTADO QUE «NO QUIERE O NO PUEDE» COMBATIR EL TERRORISMO FRENTE A LA CONSOLIDACIÓN DEL DAESH}

En verano de 2014, las milicias del Daesh irrumpieron en la ciudad iraquí de Sinjar, baluarte de los yazidíes ${ }^{1}$, asesinando a unas 500 y apresando a unas 300 mujeres para esclavizarlas ${ }^{2}$. Ante esta situación, tras la invitación de Iraq, los Estados Unidos, Australia, Francia y el Reino Unido lanzaron operaciones aéreas para suministrar alimentos a los sitiados por los terroristas del Daesh ${ }^{3}$. Al mismo tiempo, la aproximación de los yihadistas a Erbil, capital del Kurdistán iraquí y zona petrolífera neurálgica para los intereses estadounidenses, movió al entonces Presidente Obama a autorizar ataques aéreos contra algunas posiciones yihadistas cerca de la ciudad ${ }^{4}$. Tras estas primeras incursiones aéreas, Barack Obama anunció el comienzo de una operación militar (más tarde denominada Determinación absoluta ${ }^{5}$ ) para combatir el Daesh en Iraq y Siria, y que cuenta en la actualidad con 79 Estados participantes ${ }^{6}$.

1 Los yezidíes son una minoría religiosa de etnia kurda que practica un credo en el que se mezclan elementos de zoroastrismo, cristianismo e islamismo. Véase, EcheverRÍA JEsús, C., «El Estado Islámico (EI) como grupo terrorista yihadista salafista y otros grupos armados violentos actuando en Irak hoy», Instituto Español de Estudios Estratégicos, Documento de investigación, n. ${ }^{\circ}$ 6, 2014, pp. 1-15, p. 7.

2 A/HRC/32/CRP.2, de 15 de junio de 2016, «They came to destroy»: ISIS Crimes Against the Yazidis, párr. 165 .

3 Statement by the President, The White House, de 7 de agosto de 2014, disponible en: https:// www.whitehouse.gov/thepress-office/2014/08/07/statement-president

4 BASSETS, M., «Obama autoriza ataques limitados en Irak para frenar a los insurgentes suníes», El País, de 8 de agosto de 2014, disponible en: http://internacional.elpais.com/internacional/2014/08/08/actualidad/1407463775_200286.html

5 Alemania, Australia, Canadá, Dinamarca, los Estados Unidos, Francia, Italia, Polonia, el Reino Unido y Turquía. Véase, ABELLáN, L., «EE. UU. forja una alianza de 10 países para combatir a los yihadistas», El País, de 5 de septiembre de 2014, disponible en: http://internacional.elpais. com/internacional/2014/09/05/actualidad/1409917501_927947.html

6 Véase, https://theglobalcoalition.org/en/partners/ 
Sin ahondar en el análisis sobre la licitud o no de esta intervención mili$\operatorname{tar}^{7}$, conviene subrayar, no obstante, que sigue sin contar con la autorización expresa del Consejo de Seguridad para el recurso a la fuerza armada en Siria. A este respecto, cabe recordar la Resolución 2249 (2015), adoptada por unanimidad el 20 de noviembre de 2015, después de que un avión ruso fuera derribado en la península del Sinai ${ }^{8}$ y de los ataques terroristas de París reivindicados por el Daesh' ${ }^{9}$. Tras calificar al Daesh como «una amenaza mundial sin precedentes para la paz y la seguridad internacionales $\gg^{10}$, en el párrafo 5 de la parte dispositiva de dicha Resolución, el Consejo exhorta a los Estados a adoptar «todas las medidas necesarias» para erradicar el cobijo que el Daesh ha instaurado en Iraq y Siria ${ }^{11}$. A primera vista, la Resolución parece así autorizar el uso de la fuerza en ambos Estados; sin embargo, no hace referencia alguna al Capítulo VII de la Carta ni a su artículo 42, ya que tan solo «exhorta» a los Estados a adoptar «todas las medidas necesarias» contra el Daesh, pero sin autorizar ninguna medida más concreta. Solo anima a los Estados a proseguir con la operación Determinación absoluta, sin proporcionar ninguna base jurídica autónoma para recurrir a la fuerza armada ${ }^{12}$.

A la luz de la falta de una autorización expresa del Consejo de Seguridad pueden plantearse ciertos interrogantes sobre la licitud de esta campaña militar. Mientras la vertiente iraquí de la operación no suscita dudas jurídicas, porque cuenta con la invitación a intervenir por parte de $\mathrm{Iraq}^{13}$, su ampliación

7 Para ello, véase, Bermejo García, R., «Las denominadas nuevas tendencias en la lucha contra el terrorismo internacional: el caso del Estado Islámico», en GuTiérREZ EsPADA, C.; CERVELL Hortal, M. J. (eds.), El Estado Islámico (Daesh). ¿Aprenderemos la lección?, Valencia, Tirant Lo Blanch, 2018, pp. 149-223, pp. 183-215.

8 Bonet, P., «Rusia reconoce que el siniestro del avión en Egipto fue un atentado», El País, de 18 de noviembre de 2015, disponible en: https://elpais.com/internacional/2015/11/17/actualidad/1447749369_618435.html

9 HernándeZ Velasco, I., «Atentados en París: 130 muertos y 352 heridos», El Mundo, de 14 de noviembre de 2015, disponible en: https://www.elmundo.es/internacional/2015/11/14/564758 67268e3edf198b45d6.html

10 S/RES/2249, 20 de noviembre de 2015, preámbulo, párr. 5.

11 Ibid., dispositivo, párr. 5.

12 Couzigou, I., «The Fight against the 'Islamic State' in Syria: Towards the Modification of the Right to Self-Defence?», Geopolitics, History, and International Relations, vol. 9, 2017, n. ${ }^{\circ}$ 2, pp. 80-106, p. 83; Pozo SERrano, P., «El uso de la fuerza contra el Estado Islámico en Irak y Siria: problemas de fundamentación jurídica», Anuario Español de Derecho Internacional, vol. 32, 2016, pp. 141-188, p. 184.

13 S/2014/691, Carta de fecha 20 de septiembre de 2014, dirigida a la Presidenta del Consejo de Seguridad por el Representante Permanente del Iraq ante las Naciones Unidas, p. 2; S/2014/440, 
al territorio sirio es más cuestionable, desde el punto de vista jurídico. Como es bien sabido, desde hace ocho años se está librando en Siria una guerra civil que ha provocado alrededor de 560.000 muertos ${ }^{14}$ y más de 5 millones de refugiados ${ }^{15}$. Simplificando mucho, el origen del conflicto puede remontarse a la propagación por buena parte del Norte de África y varios países de Oriente Próximo de los movimientos nacidos de las fracasadas «primaveras árabes» que han causado el desplome de varios Estados (Egipto, Libia, Siria e Yemen), la reafirmación de órdenes tribales y étnicos y el auge de grupos terroristas como el Daesh. En efecto, el Daesh, pese a ser una banda terrorista nacida en Iraq ${ }^{16}$, gracias a los arrolladores éxitos obtenidos en territorio iraquí pudo extender sus ambiciones de conquista también a la vecina Siria. Allí, tomó partido contra el gobierno de Bashar Al-Assad, representante de la minoría chií de los alauíes en un Estado en su mayoría sunní, y que en pocos meses supo imponerse sobre los demás grupos rebeldes haciéndose así con amplias regiones en el noreste del país, ricas en yacimientos de petróleo. Se estima así que el Daesh, en el momento de su máxima expansión territorial que alcanzaba unos $90.800 \mathrm{~km}^{2}$, disponía de entre 1 y 3 millones de dólares diarios, derivados prevalentemente de la extracción de crudo ${ }^{17}$.

Decíamos que la extensión de la operación Determinación absoluta a Siria ha creado un gran debate doctrinal y político, porque el gobierno de Al-Assad nunca consintió que la operación actuase contra el Daesh en su territorio, ni

Carta de fecha 25 de junio de 2014, dirigida al Secretario General por el Ministro de Relaciones Exteriores del Iraq, pp. 2-3.

14 Véase, «560,000 Killed in Syria's War According to Updated Death Toll», Haaretz, de 10 de diciembre de 2018, disponible en: https://www.haaretz.com/middle-east-news/syria/560-000killed-in-syria-s-war-according-to-updated-death-toll-1.6700244

15 ACNUR, Informe anual 2017, pp. 1-31, p. 15, disponible en: https://eacnur.org/files/reports/file/ memoria_anual_de_acnur_2017.pdf

16 BARKeR, B., «ISIS: Nothing New Under The Sun», Fournal of Counterterrorism \& Homeland Security International, vol. 20, 2014, n. ${ }^{\circ}$ 4, pp. 10-12; GONZÁLEZ HERNÁNDEZ, M., «Definiendo términos: fundamentalismo, salafismo, sufismo, islamismo, wahabismo», Instituto Español de Estudios Estratégicos, Documento de Opinión, vol. 88, 2015, pp. 1-12; RoONEY, M., «El 'Estado Islámico': la ruta a la autoproclamación de un califato contemporáneo», Agenda Internacional, vol. 34, 2016, pp. 49-76, p. 63.

17 Además de otras actividades ilegales como la extorsión, el secuestro, el saqueo de antigüedades, la expropiación y la imposición de la jizya (una antigua tasa impuesta a las minorías no musulmanas). Véase, Fillingham, Z., «Is Islamic State a State?», Geopolitical Monitor, de 5 de agosto de 2015, disponible en: https://www.geopoliticalmonitor.com/is-islamic-state-a-state/; WING, N.; Kolodny, C., «15 Shocking Numbers That Will Make You Pay Attention To What ISIS Is Doing In Iraq», The Huffington Post, de 11 de agosto de 2014, disponible en: http://www. huffingtonpost.com/2014/08/11/isis-iraq-numbers_n_5659239.html 
cuenta con la autorización expresa del Consejo de Seguridad bajo el Capítulo VII de la Carta. Para justificarla varios Estados invocaron, entonces, el derecho de legítima defensa del artículo 51 de la Carta. Por ejemplo, la representante permanente de los Estados Unidos ante la ONU recordó que el Daesh utilizaba posiciones seguras situadas en Siria para planificar y realizar ataques contra Iraq, representado una amenaza para él y otros países, entre ellos los propios Estados Unidos. Por tanto, alegó la legítima defensa del artículo 51 porque «[...] el Gobierno del Estado donde se encuentra la amenaza no quiere o no puede impedir que su territorio se utilice para realizar los ataques» ${ }^{18}$. Se reintroducía así en el discurso internacional la doctrina del Estado que «no quiere o no puede» combatir el terrorismo internacional que se desarrolla en su interior.

Como explica la profesora María José Cervell Hortal, todo Estado es el responsable principal de la seguridad de su territorio y debe impedir que se utilice para preparar y realizar atentados terroristas en otros Estados. En caso contrario, el Estado víctima puede adoptar las medidas necesarias, incluso la legítima defensa, para combatir la amenaza terrorista ${ }^{19}$. Desde entonces, Washington ha mantenido siempre su postura, pese al cambio de presidencia en noviembre de 2016. Aunque no exista un reconocimiento explícito de la teoría del Estado que «no quiere o no puede» por ningún miembro de la Administración Trump, en un intercambio de cartas entre el senador demócrata Kaine, el antiguo Secretario de Estado Tillerson, y el entonces Secretario de Defensa Mattis, se afirma que el fundamento jurídico para combatir el Daesh en Siria no ha variado con el cambio de presidencia ${ }^{20}$. Aún más claramente, en una carta de agosto de 2017 del Departamento de Estado dirigida al Presidente del Comité de Relaciones Exteriores del Senado norteamericano, Bob Corker, se lee que:

«[T]he Syrian Government has shown it cannot, or will not, confront these safe havens. [...] Therefore, consistent with the inherent right of individual and collective self-defense, the United States initiated necessary and proportionate actions in Syria against ISIS in 2014 [...]. Such necessary and

18 S/2014/695, Carta de fecha 23 de septiembre de 2014, dirigida al Secretario General por la Representante Permanente de los Estados Unidos de América ante las Naciones Unidas, p. 1.

19 Cervell Hortal, M. J., «Sobre la doctrina «Unwilling or Unable State» (¿Podría el fin justificar los medios?)», Revista Española de Derecho Internacional, vol. 70, 2018, n. ${ }^{\circ}$ 1, pp. 77-100, p. 78

20 Véase, https://www.documentcloud.org/documents/4383185-Kaine-Trump-ISIS-war-powerletters.html 
proportionate measures include the use of force to defend U.S., Coalition, and U.S.-supported partner forces from threats by Syrian Government and pro-Syrian Government forces» ${ }^{21}$.

Los Estados Unidos no son los únicos que se apoyan en la doctrina del Estado que «no quiere o no puede» para defender la ampliación de los bombardeos aéreos contra el Daesh en el territorio de Siria. Aunque solo una minoría de los Estados que declararon actuar en legítima defensa fundamentaran su intervención en esta teoría, se trata de países de cierto peso en el tablero internacional, como Australia ${ }^{22}$ o Turquía ${ }^{23}$. Asimismo, el Encargado de Negocios interino de la Misión permanente de Canadá ante la ONU apuntó que: «En virtud del Artículo 51 [...] es necesario que los Estados puedan actuar en ejercicio del derecho de legítima defensa cuando el gobierno del Estado del que proviene una amenaza no tenga la voluntad o la capacidad de impedir los ataques desde su territorio» ${ }^{24}$. Igualmente, el Reino Unido -pese a no reafirmarlo ante la $\mathrm{ONU}^{25}$ - justificó su participación en la coalición internacional aludiendo a la teoría del Estado que «no quiere o no puede». El entonces Primer Ministro británico, David Cameron, afirmó en la House of Commons que: «[T]he Assad regime is unwilling and/or unable to take action necessary to prevent ISIL's continuing attack on Iraq, or indeed attacks on us» ${ }^{26}$. Otros Estados recurrieron a la teoría de forma implícita, como Alemania y Bélgica. Berlín subrayó que el Daesh:

$\ll[\mathrm{H}] \mathrm{a}$ ocupado una determinada parte del territorio sirio sobre la cual el Gobierno de la República Árabe Siria no ejerce un control efectivo en este momento. Por lo tanto, está justificado que, con arreglo al artículo 51 de la

21 Véase, https://assets.documentcloud.org/documents/3911844/8-2-17-Corker-Response.pdf (Cursiva añadida)

22 S/2015/693, Carta de fecha 9 de septiembre de 2015, dirigida al Presidente del Consejo de Seguridad por la Representante Permanente de Australia ante las Naciones Unidas, p. 2.

23 S/2015/563, Carta de fecha 24 de julio de 2015 dirigida al Presidente del Consejo de Seguridad por el Encargado de Negocios interino de la Misión Permanente de Turquía ante las Naciones Unidas, p. 1.

24 S/2015/221, Carta de fecha 31 de marzo de 2015, dirigida al Presidente del Consejo de Seguridad por el Encargado de Negocios interino de la Misión Permanente del Canadá ante las Naciones Unidas, p. 1.

25 S/2014/851, Cartas idénticas de fecha 25 de noviembre de 2014 dirigidas al Secretario General y al Presidente del Consejo de Seguridad por el Representante Permanente del Reino Unido de Gran Bretaña e Irlanda del Norte ante las Naciones Unidas, p. 1.

26 Oral Answers to Questions, Syria: Legality of Airstrikes, The House of Commons, Column 1491, de 26 de noviembre de 2015, disponible en: https://publications.parliament.uk/pa/cm201516/ cmhansrd/cm151126/debtext/151126-0001.htm 
Carta de las Naciones Unidas, los Estados que han sufrido ataques armados del EIIL originados en esta parte del territorio sirio adopten las medidas necesarias de legítima defensa, aun sin el consentimiento del Gobierno de la República Árabe Siria ${ }^{27}$.

También Bélgica afirmó algo parecido, añadiendo que su acción militar no se dirigía contra el Estado sirio, sino solo contra las instalaciones y los milicianos del Daesh:

«El EIIL ha ocupado una parte del territorio sirio sobre la cual el Gobierno de la República Árabe Siria no ejerce un control efectivo en este momento. Ante esta situación excepcional, está justificado que, con arreglo al Artículo 51 de la Carta, los Estados que han sufrido ataques armados del EIIL originados en esa parte del territorio sirio adopten medidas necesarias de legítima defensa. En ejercicio del derecho de legítima defensa colectiva, Bélgica apoyará las medidas militares de los Estados que han sufrido ataques del EIIL. Esas medidas están dirigidas contra el denominado «Estado Islámico en el Iraq y el Levante», no contra la República Árabe Siria» ${ }^{28}$.

Como se apuntaba antes, con el comienzo de las operaciones militares en Siria, algunos Estados han reintroducido en el discurso internacional la teoría del Estado que «no quiere o no puede». En efecto, la teoría no es nueva, porque algunos autores ya la vislumbraron hace décadas y ciertos Estados se sirvieron de ella en varias ocasiones para justificar sus incursiones armadas en el territorio de otro Estado sin su consentimiento ni la autorización del Consejo de Seguridad. Por ejemplo, en 1961, el profesor Fawcett apuntó que el artículo 51 de la Carta admite la intervención armada para destruir las bases de una banda armada, si las autoridades del Estado territorial no pueden o no quieren controlarla ${ }^{29}$. En tiempos más recientes, la Chatham House destacó que la legítima defensa no se limita a la respuesta contra el ataque armado de otro Estado sino también contra los actores no estatales ubicados en el Estado territorial. Especificó así que en este caso: $\ll[\mathrm{I}] \mathrm{t}$ must be evident that that

7 S/2015/946, Carta de fecha 10 de diciembre de 2015, dirigida a la Presidenta del Consejo de Seguridad por el Encargado de Negocios interino de la Misión Permanente de Alemania ante las Naciones Unidas, p. 1.

28 S/2016/523, Carta de fecha 7 de junio de 2016, dirigida al Presidente del Consejo de Seguridad por la Representante Permanente de Bélgica ante las Naciones Unidas, p. 1.

29 FAwCETT, J. E., «Intervention in International Law: A Study of Some Recent Cases», Recueil des Cours de l'Académie de Droit International, vol. 103, 1961, n. ${ }^{\circ}$ 2, pp. 347-421, p. 363. 
State is unable or unwilling to deal with the non-state actors itself and that it is necessary to use force from outside to deal with the threat in circumstances where the consent of the territorial state cannot be obtained $\gg^{30}$. Del mismo modo, el Danish Institute for International Studies corroboró que es lícita la legítima defensa contra los ataques de actores privados si el Estado territorial no quiere o no puede eliminar la amenaza de nuevos ataques:

«If the right of self-defence in such a case is to be exercised in the territory of another State, it must be evident that that State is unable or unwilling to deal with the non-state actors itself and that it is necessary to use force from outside to deal with the threat in circumstances where the consent of the territorial state cannot be obtained. [...] There is no reason to limit a State's right to protect itself from an attack by another State. The right of self-defence is a right to use force to avert an attack. The source of the attack, whether a State or a non-state actor, is irrelevant to the existence of the right ${ }^{31}$.

En cuanto a la práctica internacional, conviene destacar cómo, desde 1996, Turquía ha fundamentado sus acciones armadas en territorio iraquí contra el Partido de los Trabajadores de Kurdistán (PKK) en la incapacidad de Iraq de derrotar a los terroristas del PKK y desmantelar sus bases operativas en el norte del país, sin, no obstante, imputar los ataques a Iraq ${ }^{32}$. Cabe señalar que estas intervenciones apenas recibieron condenas por parte de la comunidad internacional e, incluso, recogieron cierto apoyo internacional, como el de los Estados Unidos ${ }^{33}$. En 2002, Rusia invocó la legítima defensa para su acción en Georgia contra los rebeldes chechenos autores de unos atentados

30 The Chatham House, «Principles of International Law on the Use of Force in Self-Defence», Int'l \& Comp. L.Q., vol. 55, 2006, n. ${ }^{\circ}$ 4, pp. 963-972, p. 969.

31 Danish Institute for International Studies, New Threats and the Use of Force, 2005, pp. 1-189, p. 69, disponible en: https://www.diis.dk/en/research/new-threats-and-the-use-offorce

32 S/1996/479, Carta de fecha 21 de junio de 1996 dirigida al Secretario General y al Presidente del Consejo de Seguridad por el Ministro de Relaciones Exteriores de Turquía, p. 1.

33 Morr, L., «Action Against Host States of Terrorist Groups», en Weller, M. (ed.), The Oxford Handbook of the Use of Force in International Law, 2016, disponible en: http://www.oxfordhandbooks.com/view/10.1093/law/9780199673049.001.0001/oxfordhb-9780199673049-e-33; RUYS, T., «Quo Vadit Jus ad Bellum? A Legal Analysis of Turkey's Military Operations Against the PKK in Northern Iraq», Melbourne Fournal of International Law, vol. 9, 2008, n. ${ }^{\circ} 2$, pp. 334364; US Department of State Press Briefings, de 18 de agosto de 2011, disponible en: http://www. state.gov/r/pa/prs/dpb/2011/08/170709.htm\#TURKEY 
en territorio ruso y la justificó por la presencia de enclaves terroristas fuera del control del Gobierno georgiano que no podía o no quería enfrentarse a la amenaza terrorista chechena ${ }^{34}$. Asimismo, Israel lleva años apelando a esta doctrina en su lucha contra los ataques terroristas provenientes del Líbano realizados por Hezbollah y la Organización para la Liberación de Palestina ${ }^{35}$. Así, en 2006, Israel justificó su campaña militar en el Líbano como un acción en legítima defensa contra Hezbollah por el lanzamiento de cohetes que causaron ocho muertos y por el secuestro de dos soldados israelíes, y atribuyó la responsabilidad de ello al Gobierno libanés por su «ineptitud y pasividad» en el ejercicio de su jurisdicción territorial ${ }^{36}$. Comentado la actuación israelí contra Hezbollah, una voz autorizada como la de la profesora Mary O'Connell sostuvo que si un Estado es «unable to prevent on-going attacks, some limited force may be used to prevent future attacks» ${ }^{37}$. Otro autor influyente como Yoram Dinstein corroboró que:

«Extra-territorial law enforcement is a form of self-defence, and it can be undertaken by Utopia against terrorists and armed bands inside Arcadian territory only in response to an armed attack unleashed by them from that territory. Utopia is entitled to enforce international law extra-territorially if and when Arcadia is unable or unwilling to prevent repetition of that armed attack $»^{38}$.

De acuerdo con estos argumentos, existe una mayor predisposición en varios Estados en reconocer la teoría del Estado que «no quiere o no puede» combatir el terrorismo internacional para justificar su participación en los bombardeos contra el Daesh en legítima defensa (individual o colectiva). Su eventual admisibilidad impone, no obstante, replantearse el criterio de la

34 S/2002/1012, Carta de fecha 11 de septiembre de 2002, dirigida al Secretario General por el Representante Permanente de la Federación de Rusia ante las Naciones Unidas, p 2.

35 A/37/257-S/15132, Carta de fecha 27 de mayo de 1982, dirigida al Secretario General por el Representante Permanente de Israel ante las Naciones Unidas, pp. 1-2; S/PV.2071, de 17 de marzo de 1978, declaración del representante de Israel, Sr. Herzog, p. 7; S/PV. 2292, de 17 de julio de 1981, declaración del representante de Israel, Sr. Blum, p. 5.

36 A/60/937-S/2006/515, Carta idénticas de fecha 12 de julio de 2006, dirigida al Secretario General y al Presidente del Consejo de Seguridad por el Representante Permanente de Israel ante las Naciones Unidas, pp. 1-2.

37 O'Connell, M. E., «Evidence of Terror», Fournal of Conflict \& Security Law, vol. 7, 2002, n. ${ }^{\circ}$ 1, pp. 19-36, p. 29.

38 Dinstein, Y., War, Aggression and Self-Defence, New York, Cambridge University Press, 2001, p. 247. (Cursiva añadida) 
«atribución» de la responsabilidad internacional por los hechos ilícitos de un actor no estatal, porque dicha teoría no exige la conexión estrecha entre el grupo terrorista y el Estado territorial para consentir al Estado víctima recurrir a la legítima defensa ${ }^{39}$. Hay que tener en cuenta que, de aceptarse esta doctrina del Estado que «no quiere o no puede», se daría una mayor ampliación interpretativa al derecho de legítima defensa del artículo 51 de la Carta que la ya experimentada tras los atentados terroristas del 11-S. Los atentados de las Torres gemelas y del Pentágono supusieron la equiparación sustancial de aquellas acciones terroristas con un «ataque armado», tal y como se contempla en el artículo 51, que permite al Estado víctima invocar el derecho de legítima defensa contra el Estado que ampara al autor de los atentados ${ }^{40}$. En la actualidad sigue, no obstante, sin aclararse qué tipo de vinculo debe existir entre el Estado en cuyo territorio se despliega la legítima defensa del Estado víctima y la organización terrorista que actúa desde ese territorio ${ }^{41}$.

\section{LA ATRIBUCIÓN DE LA RESPONSABILIDAD DIRECTA AL ESTADO TERRITORIAL POR LOS ACTOS TERRORISTAS ORIGINADOS BAJO SU JURISDICCIÓN}

Para llevar a cabo sus actividades armadas, las organizaciones terroristas operan necesariamente desde un territorio que constituye la base de la soberanía de algún Estado. De ahí que el Estado víctima de un atentado, si quiere ejercer su derecho de legítima defensa contra la banda terrorista, tiene que usar la fuerza militar en el territorio del Estado desde el cual se lanzó u organizó el ataque terrorista. Sin embargo, para que la respuesta armada sea lícita, el Estado víctima del atentado debe probar que la acción terrorista es imputable al Estado territorial ${ }^{42}$. El problema de la atribución de los atentados terroristas a un Estado concreto se impuso con toda su fuerza en la comunidad internacional después del 11-S, cuando los Estados Unidos emprendieron de forma unilateral la

39 Cervell Hortal, M. J., op. cit., nota 19, p. 84.

40 Cassese, A., «Terrorism is Also Disrupting Some Crucial Legal Categories in International Law», European fournal of International Law, vol. 12, 2001, n. ${ }^{\circ}$ 5, pp. 993-1001, pp. 996-997.

41 Brunnée, J.; ToOpe, S. J., «Self-Defence Against Non-State Actors: Are Powerful States Willing But Unable To Change International Law?», International and Comparative Law Quarterly, vol. 67, 2018, n. ${ }^{\circ} 2$, pp. 263-286, p. 264.

42 VÄRK, R., «State Responsibility for Private Armed Groups in the Context of Terrorism», furidica International, vol. 11, 2006, pp. 184-193, pp. 184-185. 
operación Libertad duradera en Afganistán contra Al-Qaeda y el gobierno de facto de los talibanes. Entonces, para aclarar esta cuestión y avalar la intervención estadounidense, el debate doctrinal se centró en lo dispuesto por la Corte Internacional de Justicia (CIJ) en la sentencia sobre las Actividades militares y paramilitares en Nicaragua y contra Nicaragua de 1986. En ella hay dos puntos importantes para la cuestión relativa a la atribución de la responsabilidad internacional y la posibilidad de ejercer la legítima defensa. En primer lugar, la CIJ decidió que la participación de un Estado en la financiación, organización, entrenamiento, equipamiento y planificación de las acciones armadas de un actor no estatal, solo darían lugar a la responsabilidad internacional del Estado si se prueba que éste retuvo el «control efectivo» de dichas acciones ${ }^{43}$. En segundo lugar, determinó que un «ataque armado» puede darse también en caso de envío por el Estado de bandas armadas al territorio de otro o de «sustancial participación» del Estado en una acción militar si, por su escala y efectos, puede calificarse como «ataque armado» realizado por las fuerzas armadas estatales. No obstante, la Corte excluyó que la asistencia prestada por un Estado a unos actores privados mediante el suministro de armas o el apoyo logístico pudieran constituir casos de «sustancial participación» en sus acciones armadas ${ }^{44}$. La postura de la CIJ en el caso Nicaragua fue criticada desde el principio tanto por algunos jueces de la propia Corte, como por la doctrina internacionalista. En su opinión disidente, el juez Jennings, por ejemplo, sostuvo que se había circunscrito demasiado el concepto de «ataque armado» al no incluir la asistencia a los rebeldes a través del suministro de armas, el apoyo logístico u otro tipo de ayuda. Según el juez estadounidense, la conclusión de la Corte no reflejaba la realidad de un mundo en el que la mayoría de las guerras se desarrollaba mediante la desestabilización y el apoyo -financiero, logístico y militar- a grupos rebeldes ${ }^{45}$.

Pese al intento de la jurisprudencia internacional de suavizar el criterio del «control efectivo» en el caso Tadic, en donde el Tribunal Penal Internacional para la Antigua Yugoslavia (TPIY) escogió el más amplio criterio del «control general» ${ }^{46}$, la CIJ no se apartó del pronunciamiento de 1986 ni siquiera después

43 ICJ Reports 1986, Nicaragua v. Estados Unidos, párr. 115.

44 Ibid., párr. 195.

45 Ibid., opinión disidente del juez JENNINGS, pp. 543-544.

46 Prosecutor v. Dusko Tadic, Opinion and Judgment, 7 de mayo de 1997, párrs. 117, 131, 137, 585, 601 y 607. Según el TPIY existe un «control general» cuando el Estado: «[H]as a role in organising, coordinating or planning the military actions of the military group, in addition to financing, training and equipping or providing operational support to that group». 
del 11-S. Volvió así a corroborar su criterio del «control efectivo» en la Opinión consultiva sobre las Consecuencias jurídicas de la construcción de un muro en el territorio palestino ocupado $0^{47}$, de 2004, en la decisión sobre las Actividades armadas en el territorio del Congo ${ }^{48}$, de 2005 y en la sentencia sobre la Aplicación de la Convención para la prevención y la represión del crimen de genocidio de $2007^{49}$.

Con base en la jurisprudencia de la CIJ, por tanto, no hubiera sido posible atribuir la responsabilidad por los atentados del 11-S al gobierno de facto de los talibanes en Afganistán, ni a ningún otro Estado que respalde, logística, económica y/o militarmente a un actor no estatal como una organización terrorista. Pese a ello, es una circunstancia más que comprobada que la práctica totalidad de la comunidad internacional apoyó la operación Libertad durade$r a$, como resulta, por ejemplo, de las declaraciones en el seno de la Asamblea General $^{50}$, del Consejo de Seguridad de la $\mathrm{ONU}^{51}$, del Consejo Europeo ${ }^{52}$, o

47 ICJ Reports 2004, Consecuencias jurídicas de la construcción de un muro, párr. 139.

48 ICJ Reports 2005, República Democrática del Congo v. República de Uganda, párrs. 160 y 301. Entre las demás cuestiones, la Corte investigó si las acciones de la milicia rebelde congoleña MLC fueron ejecutadas «por instrucciones o bajo la dirección o el control» de Uganda, de conformidad al artículo 8 del Proyecto de artículos sobre la «Responsabilidad del Estado por hechos internacionalmente ilícitos», pero no encontró pruebas que lo demostrasen. Asimismo, afirmó que la falta de acción por parte de la RDC contra los grupos rebeldes en las áreas fronterizas con Uganda no equivalía a tolerar o consentir sus actividades. Reafirmó entonces la necesidad de un «control efectivo» para atribuir las acciones ilícitas de unas personas o grupos de personas (rebeldes, mercenarios o terroristas) a un Estado.

49 ICJ Reports 2007, Aplicación de la Convención para la prevención y la represión del crimen de genocidio (Bosnia y Herzegovina v. Serbia y Montenegro), párrs. 385-395 y 398-412. La Corte examinó si los autores de la masacre de Srebrenica actuaron «por instrucciones o bajo la dirección o el control» de la antigua Yugoslavia, según el artículo 8 del Proyecto de artículos sobre la «Responsabilidad del Estado por hechos internacionalmente ilícitos». Según la Corte, la prueba del «control general» parecía inapropiada porque ampliaba demasiado la relación entre el comportamiento de los órganos del Estado y su responsabilidad internacional. Por tanto, condenó a Serbia por no haber prevenido y reprimido el genocidio, como exige el artículo 1 de la Convención para la prevención y la sanción del delito de genocidio (1948). Pero, no pudo atribuirle la responsabilidad por la ejecución del genocidio según el artículo 4 del Proyecto, por no haberse probado que Serbia ejerciese un «control efectivo» sobre las milicias que perpetraron las atrocidades de Srebrenica en 1995. La Corte estimó, por tanto, que la tolerancia o la ayuda a actores privados no es suficiente para atribuir la responsabilidad a un Estado.

50 Linderfalk, U., «The Post-9/11 Discourse Revisited - The Self-Image of the International Legal Scientific Discipline», Gottingen Fournal of International Law, vol. 2, 2010, $\mathrm{n}^{\circ} 3$, pp. 895 949, pp. 924-925.

51 AFG/152-SC/7167, de 8 de octubre de 2001, Press Statement on Terrorist Threats by Security Council President, disponible en: https://www.un.org/press/en/2001/afg152.doc.htm

52 Consejo Europeo extraordinario de Bruselas: Conclusiones y Plan de Acción, de 21 de septiembre de 2001, n. 140/01, p. 1 . 
de la OTAN ${ }^{53}$. También en el ámbito doctrinal, desde el principio hubo un amplio consenso de que, ante la magnitud de aquellos hechos, a ciertos ataques terroristas no se les puede negar la índole de «ataque armado» solo porque no son acciones armadas conducidas según los métodos militares tradicionales ${ }^{54}$. Es decir, el elemento determinante para establecer la existencia de un «ataque armado» no es tanto la identificación del sujeto que realiza el ataque, sino el alcance de la agresión. Si sus efectos resultan equiparables a los que podrían haberse producido por un ataque militar tradicional se tratará de un «ataque armado», según el artículo 51 de la Carta. Esta postura parece muy sensata, porque si no se reconociera esta ampliación de la noción de «ataque armado» se favorecerían a los actores privados terroristas, asegurándoles la posibilidad de perpetrar agresiones a gran escala y con toda impunidad ${ }^{55}$. Asimismo, buena parte de la doctrina afirmó que no es necesario que el autor de una agresión calificable como «ataque armado» deba ser un Estado, pese al texto un tanto ambiguo del artículo 51 de la Carta (que solo menciona el «ataque armado contra un Miembro de las Naciones Unidas) y de su interpretación dada por la CIJ en los asuntos Nicaragua, las Consecuencias jurídicas de la construcción de un muro y las Actividades armadas en el territorio del Congo. Como destacaron, por ejemplo, los jueces Buergenthal, Higgins y Kooijmans, tras la adopción de las Resoluciones 1368 y 1373 del Consejo de Seguridad de 2001, hay que aceptar que el «ataque armado» del artículo 51 puede provenir también de un sujeto distinto de un Estado y que no es menester, en consecuencia, imputar el ataque armado a otro Estado ${ }^{56}$.

Así, tanto la práctica como la doctrina internacionales han rebajado notablemente el grado de apoyo necesario para configurar un «ataque armado»

53 NATO press release (2001) 124, de 12 de septiembre de 2001, disponible en: http://www.nato. int/docu/pr/2001/p01-124e.htm; Statement by NATO Secretary General, Lord Robertson, de 2 de octubre de 2001, disponible en: http://www.nato.int/docu/speech/2001/s011002a.htm

54 KoH, H. H., «The Spirit of the Laws», Harvard International Law fournal, vol. 43, 2002, n. ${ }^{\circ} 1$, pp. 23-40, p. 24; MURPHY, S. D., «Terrorism and the Concept of 'Armed Attack' in Article 51 of the U.N. Charter», Harvard International Law Fournal, vol. 43, 2002, n. ${ }^{\circ}$ 1, pp. 41-51, p. 51; SHAH, N. A., «Self-defence, Anticipatory Self-defence and Pre-emption: International Law's Response to Terrorism», Fournal of Conflict \& Security Law, vol. 12, 2007, n. ${ }^{\circ}$ 1, pp. 95-126, p. 108.

55 Wolfrum, R., «The Attack of September 11, 2002, the Wars Against the Taliban and Iraq: Is There a Need to Reconsider International Law on the Recourse to Force and the Rules in Armed Conflict?», Max Planck Yearbook of United Nations Law, vol. 7, 2003, pp. 1-78, p. 36.

56 ICJ Reports 2004, Consecuencias jurídicas de la construcción de un muro, declaración del juez BuERGENTHAL, párr. 6; ibid., opinión separada de la juez HigGINS, párr. 33; ibid., opinión separada del juez KoOIjMans, párr. 35. 
y para atribuir al Estado territorial la responsabilidad por las acciones de una banda terrorista a la que cobija ${ }^{57}$. Prueba de ello es la circunstancia de que los Estados siguen esforzándose por truncar las fuentes de financiación de las organizaciones terroristas, porque están convencidos de que el respaldo económico es vital para las actividades terroristas; desmintiendo así la postura de la CIJ en la sentencia Nicaragua y siguientes ${ }^{58}$. Como apuntó el juez Simma, la lectura restrictiva del concepto de «ataque armado» del artículo 51 debe reconsiderarse, porque las Resoluciones 1368 y 1373 reconocieron que los ataques de gran envergadura de actores no estatales son verdaderos «ataques armados» según el artículo 51 de la Carta ${ }^{59}$. Está claro entonces que no es posible seguir aplicando el criterio elaborado en el caso Nicaragua, porque esto implicaría que: 1) un Estado puede proporcionar armamentos, apoyo logístico y cobijo a una banda terrorista; 2) dicha banda puede realizar atentados de todo tipo, incluso con armas de destrucción masiva; 3) el Estado víctima no tiene derecho de legítima defensa contra el Estado territorial cómplice, porque su asistencia a la organización terrorista no constituye un «ataque armado»; y 4) el Estado víctima no puede responder en legítima defensa contra el grupo terrorista porque su actuación no es imputable al Estado territorial a menos que éste no haya «enviado» al grupo ${ }^{60}$. Cabe subrayar, no obstante, que la sentencia Nicaragua, así como la relativa a las Actividades armadas en el territorio del Congo, atañen a supuestos de legítima defensa contra el Estado territorial, sin ocuparse del supuesto más frecuente de la respuesta armada contra las infraestructuras y los combatientes terroristas presentes en su territorio ${ }^{61}$. Asimismo, las mencionadas decisiones de la CIJ parecen haber subestimado las dificultades concretas que conlleva la prueba por parte del

57 Sснмітт, M. N., «The Legality of Operation Iraqi Freedom under International Law», fournal of Military Ethics, vol. 3, 2004, n. ${ }^{\circ}$ 2, pp. 82-104, p. 88.

58 Proulx, V. J., «Babysitting Terrorists: Should States Be Strictly Liable for Failing to Prevent Transborder Attacks», vol. 23, 2005, n. ${ }^{\circ}$ 3, Berkeley Fournal of International Law, pp. 615-668, p. 633.

59 ICJ Reports 2005, República Democrática del Congo v. República de Uganda, opinión separada del juez SimMa, párrs. 11-12. En contra véase, SANJOSÉ GIL, A., «La legítima defensa individual y colectiva y el artículo 51 de la Carta de las Naciones Unidas», en CARDONA LlorÈns, J. (ed.), La ONU y el mantenimiento de la paz en el siglo XII: entre la adaptación y la reforma de la Carta, Valencia, Tirant Lo Blanch, 2008, pp. 329-361, p. 360, quien cree que esta ampliación no tiene ningún fundamento en la Carta, por lo que sería aceptable solo en caso de modificación del artículo 51 de la Carta.

60 MoIR, L., op. cit., nota 33.

61 Ibid. 
Estado víctima del «control efectivo» ejercido por el Estado territorial sobre una organización terrorista ${ }^{62}$.

Así pues, los ataques terroristas del 11-S propiciaron un primer cambio significativo en la legítima defensa, ya que el concepto de «atribución» de la responsabilidad estatal dio paso a las nociones de «amparo» y «apoyo» a una banda terrorista ${ }^{63}$. Desde entonces, el Derecho internacional impone un criterio de atribución de responsabilidad más laxo, por lo que los Estados que amparan a grupos terroristas pueden ser también objetivos legítimos de la acción armada en legítima defensa ${ }^{64}$. Esta tendencia creciente de la comunidad internacional a reconocer la legítima defensa contra los ataques armados de actores no estatales se hizo patente incluso en algunos tratados de defensa mutua, sobre todo en el ámbito de ciertas organizaciones regionales ${ }^{65}$. Piénsese, por ejemplo, en el artículo 1.c del Pacto de no agresión y defensa común de la Unión Africana (2005) y en los artículos 5.4 y 8.2 del Protocolo de no agresión y defensa mutua en la región de los Grandes Lagos (2006).

La interpretación restrictiva del concepto de «ataque armado», que la CIJ ha confirmado en varios pronunciamientos, sigue exigiendo el envío por un Estado, o en su nombre, de bandas armadas o su «sustancial participación» en las acciones de tales bandas en el territorio de otro Estado ${ }^{66}$. Tras los atentados del 11-S, la diferencia -nada desdeñable- es que en la noción de «sustan-

62 Cassese, A., «The Nicaragua and Tadic Tests Revisited in Light of the ICJ Judgment on Genocide in Bosnia», European fournal of International Law, vol. 18, 2007, n. ${ }^{\circ} 4$, pp. 649-668, pp. 665667.

63 Pozo Serrano, P., La guerra de Af-Pakistán y el uso de la fuerza en las relaciones internacionales, Pamplona, Eunsa, 2011, p. 83.

64 DominicÉ, C., «La société internationale à la recherche de son équilibre», Recueil des Cours de l'Académie de Droit International, vol. 370, 2013, pp. 29-392, p. 303; GUTIÉRREZ EsPADA, C., «Sobre la prohibición del uso de la fuerza armada en los últimos setenta años (1945-2015)», en en PONS Rafols, X. (dir.), Las Naciones Unidas desde España: 70 aniversario de las Naciones Unidas. 60 aniversario del ingreso de España en las Naciones Unidas, Barcelona, Asociación para las Naciones Unidas en España, 2015, pp. 125-150, p. 140; RonZITTI, N., «The Current Status of Legal Principles Prohibiting the Use of Force and Legal Justifications of the Use of Force», en Bothe, M. et al. (eds.), Redefining Sovereignty. The Use of Force after the Cold War, New York, Transnational Publishers, 2005, pp. 91-110, p. 97.

65 RoscinI, M., «Neighborhood Watch? The African Great Lakes Pact and ius ad bellum», Heidelberg fournal of International Law, vol. 69, 2009, n. ${ }^{\circ}$ 4, pp. 931-959, p. 942.

66 MoIr, L., Reappraising the Resort to Force: International Law, Fus ad Bellum and the War on Terror, Portland, Hart Publishing, 2010, p. 136; Verhoeven, S., «A Missed Opportunity to Clarify the Modern Ius ad Bellum: Case Concerning Armed Activities on the Territory of the Congo», Military Law and Law of War Review, vol. 45, 2006, n. ${ }^{\circ} 3$, pp. 355-368, p. 360. 
cial participación» caben también los casos en los que el Estado territorial ha financiado, organizado, entrenado, equipado, planificado o solo amparado un grupo terrorista. De ahí que en los supuestos de Estados víctimas de ataques terroristas de menor intensidad (en comparación con los del 11-S) o en los que el Estado territorial no ha participado ni directa ni indirectamente en los atentados, no se podría invocar la legítima defensa. Queda así abierta la cuestión de cómo el Estado víctima podría defenderse de conformidad con el Derecho internacional frente a estas situaciones ${ }^{67}$.

\section{LA CRISIS SIN REMEDIO DE LOS CRITERIOS TÍPICOS DE ATRIBUCIÓN DE LA RESPONSABILIDAD INTERNACIONAL FRENTE}

\section{AL TERRORISMO CONTEMPORÁNEO}

Ya en la sentencia relativa al caso del Canal de Corfú de 1949, la CIJ afirmó que los Estados tienen que observar la obligación consuetudinaria que les impone evitar que se utilice su territorio para la realización de actividades ilícitas contrarias a los derechos de los demás Estados ${ }^{68}$. El artículo 2 del Proyecto de artículos sobre la responsabilidad del Estado por hechos internacionalmente ilícitos, aprobado por la Comisión de Derecho Internacional (CDI) en 2001, confirma que: «Hay hecho internacionalmente ilícito del Estado cuando un comportamiento consistente en una acción u omisión: a) es atribuible al Estado según el derecho internacional; y b) constituye una violación de una obliga-

67 Brunnée, J.; Toope, S. J., Legitimacy and Legality in International Law: An Interactional Accou$n t$, New York, Cambridge University Press, 2010, p. 294, donde recuerdan que el derecho de legítima defensa es «inherente», a saber, precedente a la Carta y, por tanto, entra en juego la costumbre internacional. Con respecto a la legítima defensa, el Derecho internacional consuetudinario relevante es el que deriva del accidente del barco Caroline, donde el ataque armado inicial fue realizado por unos actores no estatales. En consecuencia, sería legítimo pensar que el artículo 51 de la Carta, interpretado a la luz del Derecho internacional consuetudinario, permite la legítima defensa ante a la agresión llevada a cabo por unos actores no estatales; TAMS, C. J., «Light Treatment of a Complex Problem: The Law of Self-Defence in the Wall Case», European fournal of International Law, vol. 16, 2006, n. ${ }^{\circ}$ 5, pp. 963-978, p. 976.

68 ICJ Reports 1949, Canal de Corfú (Reino Unido v. Albania), p. 22: «Such obligations are based, not on the Hague Convention of 1907, No. VTII, which is applicable in time of war, but on certain general and well-recognized principles, namely: elementary considerations of humanity, even more exacting in peace than in war; the principle of the freedom of maritime communication; and every State's obligation not to allow knowingly its territory to be used for acts contrary to the rights of other States». 
ción internacional del Estado» ${ }^{69}$. Según la CDI, un hecho ilícito es atribuible a un Estado si la acción o la omisión procede de un órgano estatal (art. 4 del Proyecto) o, pese a no emanar de un órgano estatal, es imputable a un Estado por una de las demás causas previstas en el Proyecto (arts. de 5 a 11). Entre estas causas, secundando el pronunciamiento de la CIJ en el caso Nicaragua, el artículo 8 del Proyecto afirma que:

«Se considerará hecho del Estado según el derecho internacional el comportamiento de una persona o de un grupo de personas si esa persona o ese grupo de personas actúa de hecho por instrucciones o bajo la dirección o el control de ese Estado al observar ese comportamiento» ${ }^{70}$.

Para atribuir la responsabilidad a un Estado por un hecho ilícito de un actor privado, la CDI sigue considerando necesario que el Estado haya dado instrucciones, dirigido o controlado la actividad ilícita del actor no estatal. Se desprende así que, en virtud del Proyecto, la conducta de actores privados no es, per se, atribuible a un Estado ${ }^{71}$.

Los atentados del 11-S demostraron, sin embargo, que una organización terrorista puede realizar ataques armados tan letales como los de un Estado, incluso sin el «control efectivo» 0 «por instrucciones o bajo la dirección o el control» del Estado territorial. En consecuencia, la regla enunciada en el artículo 2 del Proyecto se ha quedado un tanto obsoleta o, al menos, resulta matizable en cuanto a la lucha contra el terrorismo internacional. La disposición puede ser válida en relación con casos, como los de Nicaragua o Tadic, en donde los actores no estatales tenían un vínculo estrecho con el Estado territorial o actuaban de hecho como órganos estatales, pero no se adapta a las formas contemporáneas del terrorismo ${ }^{72}$. La aplicación obstinada a las acciones de bandas terroristas del criterio de atribución previsto en las normas sobre la responsabilidad del Estado por hechos internacionalmente ilícitos acaba favoreciendo a estos actores privados que pueden agredir a los Estados sin que estos tengan los medios eficaces para defenderse

69 A/RES/56/83, de 28 de enero de 2002, Anexo: Proyecto de artículos sobre la responsabilidad del Estado por hechos internacionalmente ilícitos, artículo 2.a.

70 Ibid., artículo 8.

71 CRaWFORD, J., The International Law Commission's Articles on State Responsibility: Introduction, Text and Commentaries, Cambridge, Cambridge University Press, 2002, p. 91.

72 Proulx, V. J., op. cit., nota 58, p. 626. 
de forma licita ${ }^{73}$. Sería solo un formalismo perjudicial vincular la legítima defensa del Estado víctima de un atentado terrorista a su imputabilidad a un Estado en concreto ${ }^{74}$.

La operación Libertad duradera en Afganistán constituyó, por lo dicho, un cambio de paradigma en el derecho de la legítima defensa y representó una primera ampliación de la legítima defensa del Estado, que permite recurrir a ella contra los grupos armados no estatales ${ }^{75}$. Como se ha resaltado previamente, las Resoluciones 1368 y 1373 de 2001 legitimaron esta tendencia, reconociendo la legítima defensa del Estado víctima de un ataque terrorista contra el Estado que cobije a una banda terrorista. Un caso, éste, en el que anteriormente al 11-S, no se solía atribuir al Estado territorial según los criterios canónicos identificados por la CIJ en el asunto Nicaragua ${ }^{76}$.

Pero, ¿qué ocurre si el Estado territorial no tiene relación alguna con el grupo terrorista y no le presta ningún tipo de apoyo, ni económico, ni militar y ni logístico? ¿Se le puede considerar responsable internacionalmente por los actos terroristas perpetrados por una organización que usa como base su territorio? ¿Cuál es el criterio que justifica jurídicamente la respuesta armada del Estado víctima en el territorio de ese Estado que nada tiene que ver con la banda terrorista? La actual operación Determinación absoluta contra el Daesh en territorio sirio ha supuesto un nuevo impulso para que la comunidad internacional superara los requisitos del «control efectivo» y de la «sustancial participación» aplicados por la $\mathrm{CIJ}^{77}$. Con esta nueva intervención militar se ha dado un paso más, ya que se reconoce la legítima defensa del Estado víctima de un atentado ante la incapacidad del Estado territorial que «no puede» evitar que se use su territorio para preparar acciones terroristas ${ }^{78}$. Ningún problema, como es evidente, en caso de respuesta armada en legítima defensa contra el Estado territorial que «no quiere» prevenir y suprimir las acciones

73 Tsagourias, N., «Self-Defence against Non-State Actors: The Interaction between Self-defence as a Primary Rule and Self-Defence as a Secondary Rule», Leiden Fournal of International Law, vol. 29, 2016, n. ${ }^{\circ}$ 3, pp. 801-825, p. 805.

74 Greenwood, C. «International Law and the 'War Against Terrorism'», International Affairs, vol. 78, 2002, n. ${ }^{\circ}$ 2, pp. 301-317, p. 307.

75 Franck, T. M., Recourse to Force: State Action Against Threats and Armed Attacks, Cambridge, Cambridge University Press, 2002, p. 54; MoIR, L., op. cit., nota 33.

76 MoIR, L., op. cit., nota 33.

77 SCHARF, M. P., «How the War against ISIS Changed International Law», Case Western Reserve Journal of International Law, vol. 48, 2016, pp. 15-67, p. 66.

78 BRUnNÉE, J.; TOOPE, S. J., op. cit., nota 41, p. 264. 
del grupo terrorista. La intervención militar, en este caso, será licita y necesaria si resulta que el Estado territorial ha tolerado o apoyado las actividades terroristas de un actor no estatal bajo su jurisdicción ${ }^{79}$. Creemos, sin embargo, que la reaparición de la teoría del Estado que «no quiere o no puede» plantea una nueva ampliación de la legítima defensa frente a una forma diferente de responsabilidad: la responsabilidad «objetiva» e «indirecta» del Estado. Dicha responsabilidad se da cuando no existe ningún vínculo entre el actor no estatal autor de un ilícito y el Estado territorial, por lo que, según la doctrina y la jurisprudencia internacionales analizadas hasta ahora no sería posible atribuirle a ese Estado el hecho ilícito. El reconocimiento de una responsabilidad objetiva e indirecta permitiría afirmar que un Estado es, a primera vista, responsable también de los actos no cometidos por sus órganos ni respaldados por él. Este tipo de responsabilidad se daría también en el caso en que no sea posible imputar el hecho ilícito, consistente en una acción u omisión, a un órgano estatal según el artículo 4 del Proyecto, o cuando el actor privado no «actúa de hecho por instrucciones o bajo la dirección o el control» de un Estado en virtud del artículo 8 del Proyecto. Se debe distinguir, por tanto, de la responsabilidad «directa» porque, mientras esta deriva de la realización voluntaria de un acto o una omisión perjudiciales, la responsabilidad «objetiva»e «indirecta» procede de la incapacidad de tomar las medidas necesarias para prevenir y castigar el ilícito internacional ${ }^{80}$. En ambos casos, el Estado territorial viola una obligación internacional, pero en el caso de la responsabilidad «objetiva» e «indirecta» la violación consta de una omisión involuntaria del Estado territorial frente a la amenaza terrorista autóctona ${ }^{81}$.

La responsabilidad objetiva internacional tiene su origen en el principio sic utere tuo ut alienum non laedas («utiliza lo tuyo de tal modo que no perjudique a lo ajeno»), desarrollado a partir de las normas nacionales para la defensa

79 Lubell, N., Extraterritorial Use of Force against Non-State Actors, New York, Oxford University Press, 2010, p. 42; MoIR, L., op. cit., nota 33; SCHMITT, M. N., «'Change direction’ 2006: Israeli operations in Lebanon and the International Law of Self-Defense», Michigan fournal of International Law, vol. 29, 2008, n. ${ }^{\circ}$ 2, pp. 127-164, p. 161; TrAPP, K., «Can Non-State Actors Mount an Armed Attack?», en WELLER, M. (ed.), The Oxford handbook of the Use of Force in International Law, 2016, pp. 680-696, pp. 695-696.

80 BROWN, D., «Use of Force against Terrorism after September $11^{\text {th: }}$ : State Responsibility, Self-Defense and Other Responses», Cardozo fournal of International and Comparative Law, vol. 11, 2003, n. ${ }^{\circ} 1$, pp. 1-54, p. 13.

81 CRAWFORD, J., «The ILC's Articles on Responsibility of States for Internationally Wrongful Acts: A Retrospect», The American fournal of International Law, vol. 96, 2002, n. ${ }^{\circ} 4$, pp. 874-890, p. 878; ProulX, V. J., op. cit., nota 58, p. 624. 
de los consumidores y aplicado, sobre todo, en el ámbito del Derecho internacional del medio ambiente ${ }^{82}$. Así, por ejemplo, en unas de las primeras decisiones sobre este asunto, la Escola v. Coca Cola Bottling Company, el fabricante fue condenado por no haber sabido garantizar la cualidad de su producto en virtud del principio de la responsabilidad objetiva, que impone al fabricante sobrellevar el coste de los daños causados por sus productos, sin que sean los consumidores perjudicados en tener que soportarlo ${ }^{83}$. Según el profesor Vincent-Joël Proulx se puede instituir un paralelismo entre este enfoque en favor del consumidor y una legislación internacional antiterrorista en pro de la población civil ${ }^{84}$. En efecto, no faltan a nivel internacional ejemplos en este sentido; podemos recordar aquí como el Tribunal arbitral que juzgó el asunto Trail Smelter afirmó que los Estados tienen en todo momento la obligación de proteger los demás Estados de los actos perjudiciales de los individuos bajo su jurisdicción ${ }^{85}$. Por su parte, en la Opinión consultiva sobre la Legalidad de la amenaza o uso de las armas nucleares de 1996, la CIJ constató la existencia de una obligación internacional que impone a todo Estado asegurar que las actividades realizadas bajo su jurisdicción respeten el medio ambiente de los demás Estados para prevenir así los daños transfronterizos ${ }^{86}$. Entonces, si bien es cierto que el principio sic utere tuo ut alienum non laedas se ha consolidado en el Derecho internacional medioambiental, la obligación de prevenir daños

82 Proulx, V. J., op. cit., nota 58, p. 652: «Although not directly transposable to international law per se, we can consider domestic products liability law as a philosophically similar phenomenon to the war on terrorism».

83 Véase, Proulx, V. J., op. cit., nota 58, pp. 652-653; Escola v. Coca Cola Bottling Co., 150 P.2d 436, 24 Cal. 2d 453, 1944 Cal. Lexis 248 (Cal. 1944), disponible en: https://www.lexisnexis.com/ lawschool/resources/p/casebrief-escola-v-coca-cola-bottling-co-of-fresno.aspx

84 Proulx, V. J., op. cit., nota 58, p. 653: «This pro-consumer approach can easily be analogized to terrorist attacks emanating from a given territory, namely through a pro-civilian posture vis- $\grave{a}-$ vis terrorism».

85 Trail Smelter case (United States v. Canada), Reports of International Arbitral Awards, vol. III, 2006, pp. 1905-1982, p. 1963, disponible en: http://legal.un.org/riaa/cases/vol_III/1905-1982. pdf: «As Professor Eagleton puts in (Responsibility of States in International Law, 1928, p. 80): 'A State owes at all times a duty to protect other States against injurious acts by individuals from within its jurisdiction.' A great number of such general pronouncements by leading authorities concerning the duty of a State to respect other States and their territory have been presented to the Tribunal. These and many others have been carefully examined. International decisions, in various matters, from the Alabama case onward, and also earlier ones, are based on the same general principle, and, indeed, this principle, as such, has not been questioned by Canada».

86 ICJ Reports 1996, Legalidad de la amenaza o el empleo de armas nucleares, párr. 29. Este mismo concepto fue reafirmado por la CIJ en el caso relativo Proyecto Gabcíkovo-Nagymaros (Hungría contra Eslovaquia), párr. 53. 
transfronterizos podría aplicarse por analogía a la amenaza terrorista, tomando en consideración lo previsto en otras ramas del orden internacional ${ }^{87}$. Los Estados territoriales son los que mejor pueden evitar los ataques terroristas, así como las empresas son las que mejor pueden conocer y hacer frente a los potenciales efectos peligrosos de sus actividades ${ }^{88}$. Tampoco faltan ejemplos en los que el Derecho internacional aplica el criterio de la responsabilidad «objetiva» e «indirecta» en otros ámbitos. Piénsese así en las normas relativas a las misiones diplomáticas y a las inmunidades de las que gozan sus locales y su personal, como los artículos 22, 29 o 30 de la Convención de Viena sobre Relaciones Diplomáticas de $1961^{89}$, que imponen una serie de deberes de protección con independencia de la capacidad efectiva para cumplirlos de los Estados receptores ${ }^{90}$. Igualmente, el Convenio sobre Responsabilidad internacional por daños causados por objetos espaciales de 1972, establece en que: «Un Estado de lanzamiento tendrá responsabilidad absoluta y responderá de los daños causados por un objeto espacial suyo en la superficie de la Tierra o a las aeronaves al vuelo» ${ }^{91}$. Asimismo, en el ámbito del Derecho del Mar, en la Opinión consultiva sobre las Responsabilidades y obligaciones de los Estados patrocinantes de personas y entidades respecto de actividades en la Zona de 2011, la Sala de Controversias de los Fondos Marinos del Tribunal Internacional del Derecho

87 Proulx, V. J., op. cit., nota 58, pp. 659-660; Starski, P., «Right to Self-Defense, Attribution and the Non-State Actor - Birth of the 'Unable or Unwilling' Standard?», Heidelberg Fournal of International Law, vol. 75, 2015, n. ${ }^{\circ} 3$, pp. 455-501, p. 475.

88 Proulx, V. J., op. cit., nota 58, p. 653.

89 Convención de Viena sobre Relaciones Diplomáticas (1961), Artículo 22: «1. Los locales de la misión son inviolables. Los agentes del Estado receptor no podrán penetrar en ellos sin consentimiento del jefe de la misión. 2. El Estado receptor tiene la obligación especial de adoptar todas las medidas adecuadas para proteger los locales de la misión contra toda intrusión o daño y evitar que se turbe la tranquilidad de la misión o se atente contra su dignidad. 3. Los locales de la misión, su mobiliario y demás bienes situados en ellos, así como los medios de transporte de la misión, no podrán ser objeto de ningún registro, requisa, embargo o medida de ejecución»; Artículo 29: «La persona del agente diplomático es inviolable. No puede ser objeto de ninguna forma de detención o arresto. El Estado receptor le tratará con el debido respeto y adoptará todas las medidas adecuadas para impedir cualquier atentado contra su persona, su libertad o su dignidad»; Artículo 30: «1. La residencia particular del agente diplomático goza de la misma inviolabilidad y protección que los locales de la misión. 2. Sus documentos, su correspondencia y, salvo lo previsto en el párrafo 3 del Artículo 31, sus bienes, gozarán igualmente de inviolabilidad».

90 Crawford, J., Brownlie's Principles of Public International Law, Oxford, Oxford University Press, 2008, p. 357.

91 Convenio sobre Responsabilidad internacional por daños causados por objetos espaciales (9172), artículo 2. (Cursiva añadida) 
del Mar negó que la rigurosidad de las obligaciones de protección del medio marino pudiera variar según el nivel de desarrollo de los Estados, porque, de lo contrario, se pondría en peligro la aplicación uniforme de los estándares más altos de protección de los mares ${ }^{92}$.

\section{LA LEGÍTIMA DEFENSA EN SIRIA: ¿UNA RESPONSABILIDAD OBJETIVA INTERNACIONAL DEL ESTADO QUE «NO PUEDE» COMBATIR EL TERRORISMO?}

En el caso de Siria no hay ningún vínculo entre la organización terrorista del Daesh y el gobierno de Bashar Al-Assad. Los atentados no son atribuibles a Siria, ya que el Daesh no es un órgano -ni de jure ni de facto- del Estado sirio, no ejerce atribuciones estatales en nombre del gobierno de Siria, ni actúa por instrucciones o bajo la dirección o el control de ese Estado ${ }^{93}$. Al contrario, las fuerzas fieles al gobierno de Al-Assad combaten contra numerosos grupos rebeldes, entre ellos el Daesh, con el apoyo externo de otros Estados como Rusia o Irán ${ }^{94}$. Estamos, por tanto, ante una situación opuesta a la de Afganistán, en donde el gobierno de facto de los talibanes proporcionaba cobijo y toleraba la

92 Sala de Controversias de los Fondos Marinos del Tribunal Internacional del Derecho del Mar, Opinión consultiva sobre las Responsabilidades y obligaciones de los Estados patrocinantes de personas y entidades respecto de actividades en la Zona, 1 de febrero de 2011, párrs. 158-159: «However, none of the general provisions of the Convention concerning the responsibilities (or the liability) of the sponsoring State 'specifically provides' for according preferential treatment to sponsoring States that are developing States. As observed above, there is no provision requiring the consideration of such interests and needs beyond what is specifically stated in Part XI. It may therefore be concluded that the general provisions concerning the responsibilities and liability of the sponsoring State apply equally to all sponsoring States, whether developing or developed. Equality of treatment between developing and developed sponsoring States is consistent with the need to prevent commercial enterprises based in developed States from setting up companies in developing States, acquiring their nationality and obtaining their sponsorship in the hope of being subjected to less burdensome regulations and controls. The spread of sponsoring States 'of convenience' would jeopardize uniform application of the highest standards of protection of the marine environment, the safe development of activities in the Area and protection of the common heritage of mankind».

93 Tsagourias, N., op. cit., nota 73, p. 805.

94 A/69/804-S/2015/152, de 3 de marzo de 2015, Cartas idénticas de fecha 26 de febrero de 2015 dirigidas al Secretario General y al Presidente del Consejo de Seguridad por el Representante Permanente de la República Árabe Siria ante las Naciones Unidas, p. 2; A/69/912-S/2015/371, de 1 de junio de 2015, Cartas idénticas de fecha 25 de mayo de 2015 dirigidas al Secretario General y al Presidente del Consejo de Seguridad por el Representante Permanente de la República Árabe Siria ante las Naciones Unidas, p. 2. 
presencia de los terroristas de Al-Qaeda. Siria, no solo no respalda al Daesh, sino que combate activamente sus acciones terroristas, aunque no siempre lograra neutralizar la amenaza que esta y otras bandas terroristas representan para los Estados vecinos y no tan vecinos ${ }^{95}$. Es, por tanto, en virtud de esta incapacidad objetiva de Siria ${ }^{96}$, como se ha visto al principio, que los Estados Unidos junto con otros Estados extendieron los bombardeos aéreos al territorio sirio, pese a la falta del consentimiento del gobierno de Al-Assad o de la autorización expresa del Consejo de Seguridad.

Con cuanto antecede, cabe preguntarse si en el Derecho internacional contemporáneo está gestándose una responsabilidad «objetiva»e «indirecta» de los Estados que «no pueden» combatir el terrorismo que se desarrolla en su territorio, pero excluyendo a aquellos que «no quieren» eliminar la amenaza terrorista. En este último caso su responsabilidad es evidente, ya que violan la obligación de prevenir los ataques terroristas, volviéndose así cómplices del grupo terrorista por prestarle apoyo y albergue ${ }^{97}$. Sin embargo, la cuestión plantea más interrogantes cuando el Estado «no puede» combatir de forma eficaz el terrorismo que se desarrolla en su territorio, aunque ponga todos los medios a su alcance para atajarlo, como ocurre en el caso de Siria.

Un antecedente que puede fundamentar esta postura se encuentra ya en el caso Tellini de 1923. Después del asesinato en territorio griego de algunos miembros de la Comisión internacional encargada de supervisar la delimitación de la frontera entre Grecia y Albania, la Sociedad de Naciones instituyó un Comité para investigar los hechos. En sus conclusiones, el Comité negó que pudiera atribuirse la muerte de los comisarios al Estado griego, pero consideró que, en circunstancias parecidas, un Estado territorial podría ser responsable internacionalmente si descuidara adoptar todas las medidas razonables para prevenir el hecho ilícito y perseguir, arrestar y enjuiciar los responsables. De suerte que, ya por aquel entonces, se podía presagiar la tendencia actual a centrar el análisis, no tanto en la relación Estado territorial-órgano estatal, sino en la conducta de dicho Estado ante el hecho ilícito realizado por un actor no estatal ${ }^{98}$.

95 Corten, O., «The 'Unwilling or Unable' Test: Has it Been, and Could it be, Accepted?», Leiden fournal of International Law, vol. 29, 2016, pp. 777-799, p. 778.

96 Ibid.

97 A/RES/56/83, de 28 de enero de 2002, Anexo: Proyecto de artículos sobre la responsabilidad del Estado por hechos internacionalmente ilícitos, artículos 2 y 16. Véase, Bethlehem, D., «Self-defense against an Imminent or Actual Armed Attack by Nonstate Actors», American Fournal of International Law, vol. 106, 2012, pp. 769-777, p. 776.

98 Proulx, V. J., op. cit., nota 58, p. 627. 
Ante situaciones de este tipo, como la que está viviéndose en la actualidad en Siria, el Estado incapaz de evitar que se utilice su territorio como base para realizar atentados terroristas debería aceptar o pedir la asistencia externa de terceros, tal y como lo hizo Iraq ${ }^{99}$. El rechazo por parte del Estado territorial de un plan efectivo y razonable de acción del Estado víctima equivaldría a colaborar con los terroristas, justificando así el recurso a la fuerza por convertirse en un Estado que «no quiere» combatir el terrorismo ${ }^{100}$. Frente a la negativa de una intervención extranjera por parte del Estado territorial, al Estado víctima de ataques terroristas no le queda otra que decidir respetar la integridad territorial del Estado que alberga el grupo terrorista o violar su integridad territorial recurriendo a un uso limitado de la fuerza contra dicho grupo ${ }^{101}$. Si bien es cierto que el Estado territorial puede no ser directamente responsable por los atentados de una banda terrorista, podría serlo, no obstante, por la incapacidad de adoptar las medidas razonables que eviten que una organización terrorista use su territorio como base para atacar a terceros ${ }^{102}$. Como aclaró la CIJ en el asunto relativo al Personal diplomático y consular de los Estados Unidos en Teherán, todo Estado tiene la «obligación categórica» de proteger a las víctimas de un ataque y de adoptar todos los «pasos apropiados» para tal fin (corroborando así la decisión del caso Tellini) ${ }^{103}$. Así que, en nuestra opinión, el

99 Couzigou, I., «The Right to Self-Defence Against Non-State Actors - Criteria of the 'Unwilling or Unable' Test», en Self-Defence Against Non-State Actors: Impulses from the Max Planck Trialogues on the Law of Peace and War, Heidelberg Fournal of International Law, vol. 77, 2017, núms. 1-2, pp. 53-55, p. 54: «The territorial State has to agree with any international assistance that is, under the given circumstances, necessary and proportionate with the aim of preventing further armed attacks perpetrated from any area under its jurisdiction. This assistance could include the use of armed force»; VÄRK, R., op. cit., nota 41, p. 192: «It would be reasonable to argue that a state only bears responsibility for activities emanating from its border if it is culpable for its acts, including omissions. But for the 'privilege' of such an exemption there has to be a balancing counter-obligation - namely, a duty to cooperate with the injured state on the scale, and in a manner, that is necessary for the removal of the terrorist group in question. In other words, if a state is not itself capable of protecting the rights of other states and eliminating threats of them, the former may not passively allow the private armed group to benefit from the shield of its sovereignty and territorial inviolability».

100 Bethlehem, D., op. cit., nota 96, p. 776.

101 Trapp, K., «Back to Basics: Necessity, Proportionality, and the Right of Self-Defence against Non-State Terrorist Actors», International and Comparative Law Quarterly, vol. 56, 2007, n. ${ }^{\circ} 1$, pp. 141-156, p. 147, nota 33: «A State's consistent failure to address its counterterrorism incapacity, where such assistance is available, could be interpreted as an unwillingness to meet its international terrorism prevention obligations».

102 The Chatham House, op. cit., nota 30, p. 970.

103 ICJ Reports 1980, Personal diplomático y consular de los Estados Unidos en Teherán (Estados Unidos v. República Islámica del Irán), párr. 61. Véase, Proulx, V. J., op. cit., nota 58, p. 628. 
deber del Estado de prevenir que su territorio se use para organizar y desplegar ataques terroristas estaría convirtiéndose en una obligación de resultado y erga omnes, de la que derivaría la responsabilidad internacional del Estado incapaz de evitarlo por violar el deber de utilizar todos los medios necesarios para impedir daños a terceros, debido de cara a toda la comunidad internacional. De lo contrario, la obligación de prevenir carecería de todo sentido ${ }^{104}$. Si se reconociera que este deber de prevención constituye una obligación de resultado, sería posible concluir, como la CIJ en el caso de la Aplicación de la Convención para la prevención y la represión del crimen de genocidio que:

$\ll[\mathrm{I}] \mathrm{t}$ is irrelevant whether the State whose responsibility is in issue claims, or even proves, that even if it had employed all means reasonably at its disposal, they would not have sufficed to prevent the commission of genocide. As well as being generally difficult to prove, this is irrelevant to the breach of the obligation of conduct in question $[\ldots] \gg^{105}$.

La calificación de este tipo de obligación como una mera obligación de comportamiento, esto es, como un deber de todo Estado de «acomodar su conducta a lo prescrito específicamente por la norma» ${ }^{106}$, pero sin alcanzar un resultado concreto, no satisface las necesidades de la comunidad internacional contemporánea. El reconocimiento de la responsabilidad de aquellos Estados que (sin haber solicitado la ayuda extranjera) intentan luchar contra las bandas terroristas, pero no consiguen resultados apreciables por falta de los medios necesarios, estaría respaldado por el artículo 12 del Proyecto de la CDI, según el cual:

«Hay violación de una obligación internacional por un Estado cuando un hecho de ese Estado no está en conformidad con lo que de él exige esa obligación, sea cual fuere el origen o la naturaleza de esa obligación» ${ }^{107}$.

Los Estados tienen el deber de prevenir que sus territorios sean utilizados por los grupos terroristas para ejecutar atentados en otros Estados. Si no se

\footnotetext{
104 ProulX, V. J., op. cit., nota 58, p. 654.

105 ICJ Reports 2007, Aplicación de la Convención para la prevención y la represión del crimen de genocidio (Bosnia y Herzegovina v. Serbia y Montenegro), párr. 430.

106 Casanovas, O.; Rodrigo, Á. J., Compendio de Derecho internacional público, Madrid, Tecnos, 2017 , p. 47.

107 A/RES/56/83, de 28 de enero de 2002, Anexo: Proyecto de artículos sobre la responsabilidad del Estado por hechos internacionalmente ilícitos, artículo 12.
} 
consigue asegurar a la comunidad internacional que el territorio de un Estado no se utiliza para realizar atentados terroristas, se le puede considerar responsable de tal acto. De esta forma, se desplazaría la carga de la prueba sobre los Estados territoriales que no han podido evitar los ataques terroristas y que deberían, en consecuencia, demostrar haber adoptado todas las medidas a su disposición para evitar la realización de atentados en el extranjero ${ }^{108}$. Trasladar la carga de la prueba al Estado territorial, desde cuyo territorio actúa la banda terrorista, tendría además la ventaja indudable de servir de estímulo para dicho Estado para cumplir con las obligaciones internacionales de prevención de los actos de terrorismo ${ }^{109}$.

En atención al riesgo evidente de abusos que este cambio supone en la interpretación de la obligación de prevenir, cabe matizar que es necesario que, antes de actuar en legítima defensa, el Estado víctima debe dejar cierto margen al Estado territorial para demostrar haber aplicado la «diligencia debida» (due diligence) y haber adoptado las medidas necesarias para hacer frente a la amenaza terrorista. El principio de la «diligencia debida» implica para todo Estado la obligación de asegurar que los intereses y los derechos de los demás Estados no serán violados bajo su jurisdicción territorial ${ }^{110}$. En concreto, con respecto al deber de prevenir el terrorismo internacional, este principio no admite excepciones fundadas en el grado de control sobre su territorio, su situación económica u otros factores ${ }^{111}$. Además, es cuestionable que el Estado territorial que no solicita o no acepta la cooperación militar externa esté poniendo de su parte sus «mejores esfuerzos» para actuar según la «diligencia debida», como requiere la CIJ en el asunto sobre la Aplicación de la Convención para la prevención y la represión del crimen de genocidio ${ }^{112}$. En consecuencia, si resultara que el Estado territorial no actuó con la diligencia debida, estaría

108 Proulx, V. J., op. cit., nota 58, p. 657.

109 BeCKer, T., Terrorism and the State: Rethinking the Rules of State Responsibility, Portland, Hart Publishing, 2006, p. 270.

110 International LaW Association, Study Group on Due Diligence in International Law, Tim Stephens (Rapporteur), Second Report, July 2016, pp. 5-6.

111 Ibid., p. 18.

112 ICJ Reports 2007, Aplicación de la Convención para la prevención y la represión del crimen de genocidio (Bosnia y Herzegovina v. Serbia y Montenegro), párr. 438: «[T]he Yugoslav federal authorities should, in the view of the Court, have made the best efforts within their power to try and prevent the tragic events then taking shape [...]. [F]or a State to be held responsible for breaching its obligation of prevention, it does not need to be proven that the State concerned definitely had the power to prevent the genocide; it is sufficient that it had the means to do so and that it manifestly refrained from using them». 
poniendo al Estado víctima «en un callejón sin salida que podría justificar la necesidad de actuar en legítima defensa» como ultima ratio ${ }^{113}$. Es cierto que, como regla general, los Estados deben actuar según la «diligencia debida» para no dañar a los demás Estados solo si tienen conocimiento de la situación potencialmente perjudicial que está desarrollándose en su interior. Pero, también que, en determinadas circunstancias, los Estados tienen la obligación especifica de recurrir a todas las medidas necesarias y a todos los recursos a su disposición para frenar y reprimir las actividades ilícitas cometidas en su jurisdicción ${ }^{114}$.

A este respecto, la profesora Ashley Deeks identifica los factores que el Estado víctima debe tener en cuenta para evaluar la voluntad y la capacidad del Estado territorial de frenar los atentados terroristas: 1) el consentimiento y la cooperación del Estado territorial en prevenir las acciones terroristas; 2) la naturaleza de la amenaza representada por la organización terrorista; 3 ) las peticiones anteriores del Estado víctima (o de otros Estados) al Estado territorial para que se ocupara de la amenaza; 4) el control que el Estado territorial ejerce sobre las áreas utilizadas por la banda terrorista y su capacidad para actuar; 5) las medidas propuestas por el Estado territorial para suprimir la amenaza terrorista; y 6) las colaboraciones previas entre el Estado víctima y el Estado territorial sobre el problema del terrorismo ${ }^{115}$.

Si de la apreciación de estos factores resultara que el Estado territorial no puede combatir al grupo terrorista y rechaza la cooperación internacional, entonces se podría invocar el principio consuetudinario de la necesidad de la legítima defensa porque, dada la incapacidad del Estado territorial para controlar su territorio, no habría otra alternativa que el recurso a la fuerza militar contra el grupo terrorista. Otra cuestión diferente sería que la legítima defensa se despliegue directamente contra el Estado territorial, en cuyo caso la respuesta armada solo sería lícita si se puede atribuir a dicho Estado la acción de la banda terrorista, configurándose así un caso de uso indirecto de la fuerza que, sin embargo, nada tiene que ver con la responsabilidad indirecta del Estado ${ }^{116}$. Recordemos que, para que la legítima defensa sea lícita según el principio de necesidad, es necesario que el Estado víctima no disponga de

\footnotetext{
113 Cervell Hortal, M. J., op. cit., nota 19, p. 97.

114 INTERNATIONAL LaW ASSOCIATION, op. cit., nota 110, p. 12.

115 DEEKs, A. S., «Unwilling or Unable: Toward a Normative Framework for Extraterritorial Self-Defense», Virginia fournal of International Law, vol. 52, 2012, pp. 483-550, pp. 519-533. 116 MOIR, L., op. cit., nota 33.
} 
otros medios alternativos y pacíficos a su alcance para hacer frente al ataque armado sufrido. La respuesta armada debe limitarse a lo estrictamente necesario para oponerse al ataque armado padecido, ni más ni menos, y debe tener una duración limitada en el tiempo. Bajo ningún supuesto, el uso de la fuerza en legítima defensa podrá tener carácter punitivo o de represalia ${ }^{117}$. Como indicaba el profesor Roberto Ago en su Adición al octavo informe sobre la responsabilidad de los Estados: «Al subrayar la exigencia del carácter necesario de la acción ejecutada en estado de legítima defensa, se quiere insistir en el hecho de que el Estado agredido (o amenazado de agresión inminente, si se admite la legítima defensa preventiva) no debe disponer en el caso de que se trate de otro medio para detener la agresión que recurrir al uso de la fuerza armada» ${ }^{118}$. Por lo tanto, también la respuesta armada del Estado víctima de un atentado terrorista que tenga sus orígenes en otro Estado tendrá que ceñirse a lo necesario para frenar la agresión y deberá durar sólo el tiempo necesario para desarrollar y completar las operaciones militares.

\section{CONCLUSIONES}

La práctica internacional a la luz de la operación Libertad duradera en Afganistán demostró que es lícita la legítima defensa ejercida contra una organización terrorista afincada en el territorio de otro Estado y que cuenta, además, con su beneplácito. Hoy en día, la operación Determinación absoluta en Siria revela que el orden internacional debería encaminarse hacia una responsabilidad «objetiva» e «indirecta» de los Estados que «no pueden» combatir las bandas terroristas, prescindiendo del criterio más clásico de la atribución al Estado territorial del artículo 8 del Proyecto de la CDI ${ }^{119}$.

Como se ha visto, el criterio identificado por la CIJ en los casos Nicaragua y otros está desconectado del contexto internacional actual, donde los grupos terroristas tienen una creciente capacidad militar, económica y tecno-

117 ICJ Reports 1996, Legalidad de la amenaza o el empleo de armas nucleares, opinión disidente de la juez Higgins, párr. 5. Véase, Schachter, O., International Law in Theory and Practice, Dordrecht, Martinus Nijhoff Publishers, 1991, p. 152.

118 A/CN. 4/SER. A/1980/Add. 1, Anuario de la CDI, 1980, vol. II, parte primera, en particular, Doc. A/CN. 4/318/Add. 5 a 7, Adición al octavo informe sobre la responsabilidad de los Estados, por el Sr. Roberto AGO - El hecho internacionalmente ilícito del Estado como fuente de responsabilidad internacional (conclusión), párr. 120. (Cursiva del autor)

${ }^{119}$ MoIR, L., op. cit., nota 33. 
lógica. La legítima defensa es un derecho «inmanente» que existe siempre que un Estado sufre un ataque, con independencia de que dimane de otro Estado o de una organización terrorista ${ }^{120}$. Como destacó el juez Simma en su opinión separada en el caso de las Actividades armadas en el territorio del Congo:

$\ll[\mathrm{I}] \mathrm{f}$ armed attacks are carried out by irregular forces from such territory against a neighbouring State, these activities are still armed attacks even if they cannot be attributed to the territorial State $[\ldots] \gg$.

Y citando al profesor Dinstein, el juez aleman recalca que: «[I]t would be unreasonable to deny the attacked State the right to self-defence merely because there is no attacker State and the Charter does not so require» ${ }^{121}$. Del mismo modo, la profesora Karin Oellers-Frahm apunta que:

«Self-defence is an «inherent right», «droit naturel» in the French version, which is triggered whenever an armed attack occurs against a state irrespective from whom it originates and irrespective of questions of imputability to the third state. [...] Consent is not necessary when the third state from where the attacks originate, is evidently unable to effectively restrain the armed activities of the non-State actors. What is at stake is the maintenance or restoration of international peace and security and whenever peace and security are endangered, even by a non-State actor, the remedies provided for in the UN Charter are applicable» ${ }^{122}$.

La eficacia y la credibilidad del Derecho internacional dependen de su capacidad para responder a los desafíos concreto de cada momento que amenazan la paz y la seguridad de la comunidad internacional. El derecho de legítima defensa del artículo 51 de la Carta puede seguir siendo efectivo en las relaciones internacionales contemporáneas, si se admite la respuesta armada del Estado víctima frente al Estado territorial en donde se cobijan los grupos terroristas, aplicando el principio de la responsabilidad «objetiva» e «indirecta» del Estado territorial. Como recuerda el profesor Cesáreo Gutiérrez

${ }^{120}$ Lowe, V., International Law, Oxford, Oxford University Press, 2007, p. 278.

${ }^{121}$ ICJ Reports 2005, República Democrática del Congo v. República de Uganda, opinión separada del juez SimMA, párr. 12; DinsteIN, Y., op. cit., nota 37, p. 216.

122 Oellers-Frahm, K., «Article 51 - What Matters Is the Armed Attack, not the Attacker», en Self-Defence Against Non-State Actors: Impulses from the Max Planck Trialogues on the Law of Peace and War, Heidelberg Journal of International Law, vol. 77, 2017, núms. 1-2, pp. 49-51, p. 50. 
Espada: $\ll[\mathrm{N}]$ o hay peor ciego que el que no quiere ver, que la realidad cambia y que no es bueno que los conceptos jurídicos se petrifiquen y vivan su propia vida desconectados del mundo real» ${ }^{123}$. Repárese en que el artículo 31 , párrafo 1, de la Convención de Viena sobre el derecho de los tratados (1969) afirma que las disposiciones de un tratado deben interpretarse según su sentido habitual y en conformidad a su objeto y fin. El artículo 31, párrafo 3.b, de la misma Convención determina que para la interpretación de un tratado habrá que tener en cuenta también las prácticas ulteriormente seguidas en la aplicación del tratado ${ }^{124}$. Se desprende así que la práctica de los Estados, no solo ayuda a dilucidar el sentido de las previsiones de un tratado, sino que puede llevar a su reajuste para que estas satisfagan la realidad internacional que deben gobernar. Cabe recordar, además, que la propia Resolución 3314 (XXIX), adoptada por la Asamblea General de la ONU, en 1974, y utilizada por la CIJ para dar su definición de «ataque armado», recuerda que ninguno de sus artículos «amplía o restringe en forma alguna el alcance de la Carta, incluidas sus disposiciones relativas a los casos en que es lícito el uso de la fuerza» ${ }^{125}$. Da a entender así que lo dispuesto en su artículo $3 . \mathrm{g}^{126}$ no es el único criterio aplicable para delimitar el concepto de «ataque armado» ${ }^{127}$.

123 GutiérReZ Espada, C., op. cit., nota 62, p. 139.

124 Convención de Viena sobre el derecho de los tratados, de 23 de mayo de 1969, artículo 31: «Regla general de interpretación: 1 . Un tratado deberá interpretarse de buena fe conforme al sentido corriente que haya de atribuirse a los términos del tratado en el contexto de estos y teniendo en cuenta su objeto y fin. 2. Para los efectos de la interpretación de un tratado. el contexto comprenderá, además del texto, incluidos su preámbulo y anexos: a) todo acuerdo que se refiera al tratado y haya sido concertado entre todas las partes con motivo de la celebración del tratado: b) todo instrumento formulado por una o más partes con motivo de la celebración del tratado y aceptado por las demás como instrumento referente al tratado; 3. Juntamente con el contexto, habrá de tenerse en cuenta: a) todo acuerdo ulterior entre las partes acerca de la interpretación del tratado o de la aplicación de sus disposiciones: b) toda práctica ulteriormente seguida en la aplicación del tratado por la cual conste el acuerdo de las partes acerca de la interpretación del tratado: c) toda forma pertinente de derecho internacional aplicable en las relaciones entre las partes. 4. Se dará a un término un sentido especial si consta que tal fue la intención de las partes».

125 A/RES/3314 (XXIX), de 14 de diciembre de 1974, artículo 6.

$126 \mathrm{Ibid}$., artículo 3.g: «[C]ualquiera de los actos siguientes, independientemente de que haya o no declaración de guerra, se caracterizará como acto de agresión: [...] El envío por un Estado, o en su nombre, de bandas armadas, grupos irregulares o mercenarios que lleven a cabo sotos de fuerza armada contra otro Estado de tal gravedad que sean equiparables a los actos antes enumerados, o su sustancial participación en dichos actos».

127 WoOD, M., «Self-Defence Against Non-State Actors - A Practitioner's View», en Self-Defence Against Non-State Actors: Impulses from the Max Planck Trialogues on the Law of Peace and War, Heidelberg Journal of International Law, vol. 77, 2017, núms. 1-2, pp. 75-77, p. 76. 
Con más razón, en el marco de la lucha contra el terrorismo internacional es fundamental que las normas internacionales aporten soluciones a los problemas que tienen que resolver, aunque esto implique un esfuerzo excepcional para evitar abusos por parte de los Estados. Es cierto que los Estados pueden aprovecharse de la teoría del Estado que «no quiere o no puede» y del criterio de la responsabilidad objetiva para perseguir sus objetivos políticos y geoestratégicos, pero esto no significa que se deba rechazar de antemano. Se han dado, y se darán en el futuro, muchos ejemplos en los que los Estados han abusado también del derecho de legítima defensa, pese a ello, no se niega la existencia y la necesidad de este derecho ${ }^{128}$. Entre los dos extremos (de un lado, «control efectivo» $\mathrm{y}$ «sustancial participación» del Estado en el atentado y, del otro, desconocimiento absoluto y total imprevisibilidad del atentado por parte del Estado territorial), existe un punto intermedio que permite aplicar un criterio decisivo para la legitima defensa, como puede ser, en este caso, el del desinterés o de la incapacidad reiterada del Estado territorial para atajar la amenaza terrorista. Si el Estado territorial quiere y puede tomar las medidas necesarias para combatir a los grupos terroristas presentes en su territorio, el Estado víctima de sus acciones no tendrá derecho a invocar ningún tipo de legítima defensa. Pero, en caso de que el Estado territorial «no quiera o no pueda», entonces la falta de voluntad o la incapacidad para combatir el terrorismo justificaría la necesidad del Estado víctima de recurrir a la legítima defensa ante la imposibilidad demostrada de confiar en la colaboración del Estado territorial ${ }^{129}$.

Las intervenciones militares de los Estados víctimas de atentados terroristas, emprendidas porque los Estados territoriales no pueden tomar medidas preventivas, cumplen con el requisito consuetudinario de la necesidad de la legítima defensa ante la ausencia de alternativas por parte del Estado víctima ${ }^{130}$.

128 Bethlehem, D., op. cit., nota 97, p. 773; Higgins, R., Problems and Process: International Law and How We Use It, Oxford, Clarendon Press, 1994, p. 247.

129 LubeLl, N., Extraterritorial Use of Force against Non-State Actors, Oxford, Oxford University Press, 2010, p. 41: «Following this approach [...] in which the territorial state is not complicit in any way in the activities of the non-state actor, but is unable to prevent these activities, leads to a similar conclusion that regardless of the legal responsibility of the territorial state, the outside state may have the right to self-defence against the non-state actor. Moreover, if the territorial state finds the non-state actor operations objectionable, but is unable to prevent them, it would avoid the need for unilateral force by the victim state were it to co-operate with that state and allow it, or others, to assist in countering the non-state actor»; TRAPP, K., op. cit., nota 101, p. 155.

130 VAN STEENBERGHE, R., «Self-Defence in Response to Attacks by Non-State Actors in the Light of Recent State Practice», Leiden Fournal of International Law, vol. 23, 2010, n. ${ }^{\circ}$ 1, pp. 183-208, pp. 199-202. 
Cuando un Estado no adopta los medios necesarios -que incluyen la solicitud de intervención externa- para evitar o reducir al mínimo la amenaza terrorista, podría considerarse licita (prima facie) la respuesta armada en legítima defensa del Estado(s) afectado(s) contra la organización terrorista ${ }^{131}$. En definitiva, como anota el profesor Lindsay Moir: «[A] host state's inability to take effective measures against armed groups operating from its territory is probably now tantamount to the level of involvement necessary to render action against those armed groups lawful» ${ }^{132}$.

Para concluir, es preciso subrayar que la tendencia de algunos Estados de atribuir la responsabilidad al Estado territorial incapaz de prevenir los atentados terroristas en el extranjero, por parte de bandas terroristas activas en su territorio, no se ha convertido todavía en una lex lata, es decir, en una norma ya existente en el Derecho internacional contemporáneo ${ }^{133}$. En la actualidad, la integridad territorial del Estado y su soberanía siguen siendo aún los principios rectores del Derecho internacional. La posibilidad de responder militarmente ante un ataque terrorista no atribuible al Estado territorial permanece, en consecuencia, en un limbo jurídico entre la prohibición del uso de la fuerza del artículo 2.4 y el derecho de legítima defensa del artículo 51 de la Carta $^{134}$. Pese a ello, la extensión de la operación Determinación absoluta al territorio de Siria confirma, con cierta claridad, la tendencia de la comunidad internacional a la aceptación de la legítima defensa de los Estados afectados ante la responsabilidad objetiva del Estado territorial que «no puede» combatir por sí solo las organizaciones terroristas presentes en su territorio.

131 Institute of International LaW, «Present Problems of the Use of Force in International Law», Sub-group on «Self-Defence», RouCOUNAS, E. (rapporteur), Yearbook of Institute of International Law, Session of Santiago de Chile, vol. 72, 2007, pp. 77-236, pp. 143-144: «In the realm of self-defence two situations are likely to appear: a) First, in case a non-State group attacks State A from the territory of State B (or also C, D, E). In that case, either the State from where the attack originated cooperates in neutralizing and sending to trial the perpetrators of the attack, or it does not cooperate. If it does not cooperate, individual and collective selfdefence could be exercised in the territory of that State B under conditions obviously stricter than those of the traditional situation of a State-to-State self-defence, since the requirement of cooperation implies a different timing and the aim will be the neutralization of the nonState entity».

132 Morr, L., op. cit., nota 33 [cursiva en el original].

133 Corten, O., «The Unwilling or Unable Test: Has it Been, and Could it Be, Accepted?», Leiden Fournal of International Law, vol. 29, 2016, pp. 777-799; MOIR, L., op. cit., nota 33; STARSKI, P., op. cit., nota 87 , pp. 489-490.

134 Trapp, K., op. cit., nota 79, p. 696. 


\section{PRINCIPALES REFERENCIAS BIBLIOGRÁFICAS}

BARKER, B., «ISIS: Nothing New Under The Sun», Fournal of Counterterrorism \& Homeland Security International, vol. 20, 2014, núm. 4, pp. 10-12.

BERMEJO GARCÍA, R., «Las denominadas nuevas tendencias en la lucha contra el terrorismo internacional: el caso del Estado Islámico», en Gutiérrez Espada, C.; Cervell HorTal, M. J. (eds.), El Estado Islámico (Daesh). ¿Aprenderemos la lección?, Valencia, Tirant Lo Blanch, 2018, pp. 149-223.

BethleheM, D., «Self-defense against an Imminent or Actual Armed Attack by Nonstate Actors», American fournal of International Law, vol. 106, 2012, pp. 769-777.

Brunnée, J.; Toope, S. J., «Self-Defence Against Non-State Actors: Are Powerful States Willing But Unable To Change International Law?», International and Comparative Law Quarterly, vol. 67, 2018, núm. 2, pp. 263-286.

Casanovas, O.; Rodrigo, Á. J., Compendio de Derecho internacional público, Madrid, Tecnos, 2017.

Cervell Hortal, M. J., «Sobre la doctrina «Unwilling or Unable State» (¿Podría el fin justificar los medios?)», REDI, vol. 70, 2018, núm. 1, pp. 77-100.

CoRTEN, O., «The 'Unwilling or Unable' Test: Has it Been, and Could it be, Accepted?», Leiden Fournal of International Law, vol. 29, 2016, pp. 777-799.

Couzigou, I., «The Fight against the 'Islamic State' in Syria: Towards the Modification of the Right to Self-Defence?», Geopolitics, History, and International Relations, vol. 9, 2017, núm. 2, pp. 80-106.

— «The Right to Self-Defence Against Non-State Actors - Criteria of the 'Unwilling or Unable' Test», en Self-Defence Against Non-State Actors: Impulses from the Max Planck Trialogues on the Law of Peace and War, Heidelberg Fournal of International Law, vol. 77, 2017, núms. 1-2, pp. 53-55.

DeEks, A. S., «Unwilling or Unable: Toward a Normative Framework for Extraterritorial Self-Defense», Virginia fournal of International Law, vol. 52, 2012, pp. 483-550.

Dinstein, Y., War, Aggression and Self-Defence, New York, Cambridge University Press, 2001.

DOMINICÉ, C., «La société internationale à la recherche de son équilibre», Recueil des Cours de l'Académie de Droit International, vol. 370, 2013, pp. 29-392.

ECHEVERRÍA Jesús, C., «El Estado Islámico (EI) como grupo terrorista yihadista salafista y otros grupos armados violentos actuando en Irak hoy», Instituto Español de Estudios Estratégicos, Documento de investigación, núm. 6, 2014, pp. 1-15.

GUTIÉRREZ EsPADA, C., «Sobre la prohibición del uso de la fuerza armada en los últimos setenta años (1945-2015)», en Pons RAFOls, X. (ed.), Las Naciones Unidas desde España: 70 aniversario de las Naciones Unidas. 60 aniversario del ingreso de España en las Naciones Unidas, Barcelona, Asociación para las Naciones Unidas en España, 2015, pp. 125-150.

International LaW Association, Study Group on Due Diligence in International Law, Tim Stephens (Rapporteur), Second Report, July 2016, pp. 1-48.

LubeLl, N., Extraterritorial Use of Force against Non-State Actors, Oxford University Press, New York, 2010.

MoIr, L., «Action Against Host States of Terrorist Groups», en WELler, M. (ed.), The Oxford Handbook of the Use of Force in International Law, Oxford University Press, 2016, pp. 1-22.

- Reappraising the Resort to Force: International Law, Jus ad Bellum and the War on Terror, Hart Publishing, Portland, 2010. 
Oellers-Frahm, K., «Article 51 - What Matters Is the Armed Attack, not the Attacker», en Self-Defence Against Non-State Actors: Impulses from the Max Planck Trialogues on the Law of Peace and War, Heidelberg Journal of International Law, vol. 77, 2017, núms. 1-2, pp. 49-51.

Pozo SERRANO, P., «El uso de la fuerza contra el Estado Islámico en Irak y Siria: problemas de fundamentación jurídica», Anuario Español de Derecho Internacional, vol. 32, 2016, pp. 141-188.

— La guerra de Af-Pakistán y el uso de la fuerza en las relaciones internacionales, Pamplona, Eunsa, 2011.

Proulx, V. J., «Babysitting Terrorists: Should States Be Strictly Liable for Failing to Prevent Transborder Attacks», Berkeley fournal of International Law, vol. 23, 2005, núm. 3, pp. 615 668.

RoONEY, M., «El 'Estado Islámico': la ruta a la autoproclamación de un califato contemporáneo», Agenda Internacional, vol. 34, 2016, pp. 49-76.

Roscini, M., «Neighborhood Watch? The African Great Lakes Pact and ius ad bellum», Heidelberg Fournal of International Law, vol. 69, 2009, núm. 4, pp. 931-959.

SCHARF, M. P., «How the War against ISIS Changed International Law», Case Western Reserve fournal of International Law, vol. 48, 2016, pp. 15-67.

STARSKI, P., «Right to Self-Defense, Attribution and the Non-State Actor - Birth of the 'Unable or Unwilling' Standard?», Heidelberg Fournal of International Law, vol. 75, 2015, núm. 3, pp. $455-501$.

The CHatham House, «Principles of International Law on the Use of Force in Self-Defence», Int'l \& Comp. L.Q., vol. 55, 2006, núm. 4, pp. 963-972.

TrAPP, K., «Back to Basics: Necessity, Proportionality, and the Right of Self-Defence against Non-State Terrorist Actors», International and Comparative Law Quarterly, vol. 56, 2007, núm. 1, pp. 141-156.

— «Can Non-State Actors Mount an Armed Attack?», en Weller, M. (ed.), The Oxford Handbook of the Use of Force in International Law, 2016, pp. 680-696.

Tsagourias, N., «Self-Defence against Non-State Actors: The Interaction between SelfDefence as a Primary Rule and Self-Defence as a Secondary Rule», Leiden Fournal of International Law, vol. 29, 2016, núm. 3, pp. 801-825.

Wood, M., «Self-Defence Against Non-State Actors - A Practitioner's View», en Self-Defence Against Non-State Actors: Impulses from the Max Planck Trialogues on the Law of Peace and War, Heidelberg Fournal of International Law, vol. 77, 2017, núms. 1-2, pp. 75-77. 
